\title{
Article

Robust Crosslinked Stereocomplexes and C60 Inclusion Complexes of Vinyl-Functionalized Stereoregular Polymers Derived from Chemo/Stereoselective Coordination Polymerization

Fernando Vidal, Laura Falivene, Lucia Caporaso, Luigi Cavallo, and Eugene Y.-X. Chen

J. Am. Chem. Soc., Just Accepted Manuscript • DOI: 10.1021/jacs.6b04064 • Publication Date (Web): 07 Jul 2016

Downloaded from http://pubs.acs.org on July 13, 2016

\section{Just Accepted}

"Just Accepted" manuscripts have been peer-reviewed and accepted for publication. They are posted online prior to technical editing, formatting for publication and author proofing. The American Chemical Society provides "Just Accepted" as a free service to the research community to expedite the dissemination of scientific material as soon as possible after acceptance. "Just Accepted" manuscripts appear in full in PDF format accompanied by an HTML abstract. "Just Accepted" manuscripts have been fully peer reviewed, but should not be considered the official version of record. They are accessible to all readers and citable by the Digital Object Identifier (DOI®). "Just Accepted" is an optional service offered to authors. Therefore, the "Just Accepted" Web site may not include all articles that will be published in the journal. After a manuscript is technically edited and formatted, it will be removed from the "Just Accepted" Web site and published as an ASAP article. Note that technical editing may introduce minor changes to the manuscript text and/or graphics which could affect content, and all legal disclaimers and ethical guidelines that apply to the journal pertain. ACS cannot be held responsible for errors or consequences arising from the use of information contained in these "Just Accepted" manuscripts. 


\title{
Robust Crosslinked Stereocomplexes and $C_{60}$ Inclusion Complexes of Vinyl-Functionalized
} Stereoregular Polymers Derived from Chemo/Stereoselective Coordination Polymerization

\author{
Fernando Vidal, ${ }^{\dagger}$ Laura Falivene, ${ }^{\dagger}$ Lucia Caporaso, ${ }^{\S}$ Luigi Cavallo, ${ }^{*}, \dot{\dagger}$ and Eugene Y.-X. Chen ${ }^{*} \dagger$ \\ ${ }^{\dagger}$ Department of Chemistry, Colorado State University, Fort Collins, Colorado 80523-1872, USA \\ ${ }^{\ddagger}$ King Abdullah University of Science and Technology (KAUST), Physical Sciences and Engineering \\ Division, Kaust Catalysis Center, Thuwal 23955-6900, Saudi Arabia \\ § Dipartimento di Chimica e Biologia, Università di Salerno, Via Papa Paolo Giovanni II, I-84084,
} Fisciano, Italy

\begin{abstract}
The successful synthesis of highly syndiotactic polar vinyl polymers bearing the reactive pendant vinyl group on each repeat unit, which is enabled by perfectly chemoselective and highly syndiospecific coordination polymerization of divinyl polar monomers developed through this work, has allowed the construction of robust crosslinked supramolecular stereocomplexes and $\mathrm{C}_{60}$ inclusion complexes. The metal-mediated coordination polymerization of three representative polar divinyl monomers, including vinyl methacrylate (VMA), allyl methacrylate (AMA), and $N, N$-diallyl acrylamide (DAA) by $C_{\mathrm{s}}$-ligated zirconocenium ester enolate catalysts under ambient conditions exhibits complete chemoselectivity and high stereoselectivity, thus producing the corresponding vinyl-functionalized polymers with high $(92 \% r r)$ to quantitative $(>99 \% r r)$ syndiotacticity. A combined experimental (synthetic, kinetic, and mechanistic) and theoretical (DFT) investigation has yielded a unimetallic, enantiomorphic-site controlled propagation mechanism. Post-functionalization of the obtained syndiotactic vinyl-functionalized polymers via the thiol-ene click and photocuring reactions readily produced the corresponding thiolated polymers and flexible crosslinked thin film materials, respectively. Complexation of such syndiotactic vinyl-functionalized polymers with isotactic poly(methyl methacrylate) and fullerene $\mathrm{C}_{60}$ generates supramolecular crystalline helical stereocomplexes and inclusion complexes, respectively. Crosslinking of such complexes afforded robust crosslinked

*Corresponding author. E-mails: luigi.cavallo@kaust.edu.sa; eugene.chen@colostate.edu
\end{abstract}


stereocomplexes that are solvent resistant and also exhibit considerably enhanced thermal and mechanical properties as compared to the uncrosslinked stereocompexes.

\section{Introduction}

Owing to its unique feature that each enchaining monomer must be coordinated to the catalyst site, which can be rationally designed by tuning the electronic, steric, and symmetry properties of the ancillary ligand, metal-mediated coordination polymerization has evolved into arguably the most powerful technique for precisely controlling the polymerization stereochemistry. ${ }^{1}$ In the case of vinyl monomersa class of the technologically most important monomers, the metal-mediated coordination polymerization can be categorized into coordination-insertion polymerization, typically for catalytic polymerization of nonpolar olefins as well as copolymerization of nonpolar and polar olefins, ${ }^{2}$ and coordination-addition polymerizations, commonly for living or quasi-living and stereospecific polymerization of conjugated polar olefins such as acrylic monomers. ${ }^{3,4}$

Specifically focusing on polar divinyl monomers, rendering their chemoselective polymerization is important for the synthesis of vinyl-functionalized polymers, which can be post-functionalized—-through the retaining vinyl groups attached to the main chain —into a variety of useful functional materials. ${ }^{5}$ However, polymerization of such monomers with complete chemoselectivity by safeguarding one of the reactive vinyl groups while selectively polymerizing the other has been a challenging task for the radical polymerization (especially during the later stage), ${ }^{6}$ group-transfer polymerization, ${ }^{7}$ or anionic polymerization carried out at $-20{ }^{\circ} \mathrm{C}$ or above. ${ }^{8}$ In the cases where complete chemoselectivity has been achieved utilizing the Lewis pair cooperativity in the Lewis pair polymerization, ${ }^{9}$ the resulting uncrosslinked, soluble functional polymers exhibited a broad molecular weight distribution $(\nexists)$ and low tacticity, ${ }^{10}$ due to non-living and non-stereoselective features of this polymerization. In this context, coordination-addition polymerization of divinyl polar monomers is advantageous due to its high degree of 
control over polymerization characteristic, even at ambient temperature. For instance, the polymerization of allyl methacrylate (AMA) by half-metallocene yttrium catalysts was shown to be both living and chemoselective. ${ }^{11}$ Furthermore, a chiral $C_{2}$-ligated ansa-zirconocenium ester enolate complex, [rac$\left.\mathrm{C}_{2} \mathrm{H}_{4}\left(\eta^{5} \text {-indenyl }\right)_{2} \mathrm{Zr}(\mathrm{THF})\right]^{+} \quad\left[\mathrm{OC}\left(\mathrm{O}^{i} \mathrm{Pr}\right)=\mathrm{CMe}_{2}\right]\left[\mathrm{MeB}\left(\mathrm{C}_{6} \mathrm{~F}_{5}\right)_{3}\right]^{-} \quad(\mathbf{1}),{ }^{12}$ which is known to mediate stereospecific and living polymerization of simple alkyl methacrylates such as methyl methacrylate (MMA) $)^{12,13}$ and acrylamides, ${ }^{14}$ is not only completely chemoselective and living, but also highly isospecific, in the polymerization of polar divinyl monomers at ambient temperature. ${ }^{15}$ The origin of the perfect chemoselectivity and high isoselectivity arises from the catalyst site-controlled coordinationaddition mechanism that dictates exclusive conjugate additions across the methacrylic double bond that is activated via coordination of the conjugated carbonyl to the cationic, chiral $\mathrm{Zr}$ center, thus leaving the pendant $\mathrm{C}=\mathrm{C}$ bond intact.

Stereocomplexation between a pair of diastereomeric polymer chains of isotactic (it) and syndiotactic $(s t)$ poly(methylate methacrylate) (PMMA) in a typical 1/2 it-PMMA/st-PMMA ratio, when annealed in the solid state or crystallized in suitable solvents, generates a crystalline stereocomplex, $s c$ PMMA, representing a rare example of helical supramolecular structures based on a vinyl polymer. ${ }^{16}$ Polar donor solvents such as acetone, THF, DMSO and DMF are known to promote such stereocomplexation and thus referred as complexing solvents, while chlorinated solvents such as chloroform and dichloromethane decomplex the sc-PMMA polymer pair and are accordingly noncomplexing or de-complexing solvents. Although the structure of sc-PMMA has received several revisions since the first report of the sc-PMMA structure model, ${ }^{17}$ its formation can be readily identified or characterized by gelation or precipitation of the crystalline complex in a complexing solvent, a high endothermic melting-transition temperature ( $T_{\mathrm{m}}$ up to $210^{\circ} \mathrm{C}$ ) by differential scanning calorimetry (DSC), and a characteristic diffraction peak $\left(2 \theta \sim 4.35^{\circ}\right)$ by powder X-ray diffraction (pXRD). ${ }^{18,19}$ Worth noting here is that the formation of $s c$-PMMA was reported to be restricted to it-PMMA, but the ester group of the $s t$-counterpart can be modified to extend to other st-poly(methacrylate)s. ${ }^{19}$ In addition, the formation 
of $s c$-PMMA is not limited to the blending of the preformed it- and st-PMMA diastereomeric polymer pair, as in situ stereocomplexing polymerization of MMA using a pair of diastereospecific coordination polymerization catalysts has led to rapid, high-yield, ambient-temperature production of $s c$-PMMA with a high $T_{\mathrm{m}}$ of up to $217{ }^{\circ} \mathrm{C} .{ }^{20}$ Furthermore, supramolecular $s c$-PMMA/silicate nanocomposites ${ }^{21}$ were fabricated by mixing dilute THF solutions of in situ polymerized it-/st-PMMA/silicates, ${ }^{22}$ and crystalline hybrid polymer stereocomplexes between POSS (polyhedral oligomeric silsesquioxane) end-capped itand st-PMMA-POSS chains were also synthesized. ${ }^{23}$ Lastly, owing to its large helical cavity $(\sim 1 \mathrm{~nm})$, syndiotactic st-PMMA, while does not crystallize by itself, co-crystallizes with specific organic solvents such as benzene ${ }^{24}$ and encapsulates guest nanocages such as fullerenes $\mathrm{C}_{60}$ and $\mathrm{C}_{70}{ }^{25}$ and MA-POSS ${ }^{23}$ to form unique crystalline helical inclusion complexes.

In light of the above overviewed unique ability of highly syndiotactic st-PMMA to form helical supramolecular structures of stereo- and inclusion complexes, we hypothesized that highly syndiotactic vinyl-functionalized poly(methacrylate)s, synthesizable from the proposed chemoselective and syndiospecific coordination polymerization of divinyl monomers, should form stereocomplexes with itPMMA and inclusion complexes with $\mathrm{C}_{60}$ which, after crosslinking, should lead to robust, solvent and thermally resistant crosslinked stereocomplexes (Figure 1) and inclusion complexes. Such robust supramolecular stereocomplexes should solve the problem of decomplexation of the current stereocomplex and inclusion complex structures in non-complexing solvents and also enhance thermal and mechanical properties of the material. Accordingly, this report presents a full account of our work towards this central objective by first achieving chemoselective and syndiospecific polymerization of divinyl polar monomers to synthesize highly syndiotactic vinyl-functionalized polymers, next postfunctionalizing and photocrosslinking such polymers into functional materials, and finally complexing such polymers to robust supramolecular stereo- and inclusion complexes followed by crosslinking. 


\section{Results and Discussion}

Chemoselective and Syndiospecific Polymerization of Polar Divinyl Monomers. The first task of this study was to synthesize highly syndiotactic acrylic polymers carrying pendant vinyl groups via the development of chemoselective and syndiospecific polymerization. Previous reports from our group have shown neutral $C_{\mathrm{s}}$-ligated zirconocene ester enolate complexes (pre-catalysts) such as $\left[\mathrm{Ph}_{2} \mathrm{C}(\mathrm{Cp})\left(2,7-{ }^{t} \mathrm{Bu}_{2}-\right.\right.$ Flu $)] \mathrm{Zr}\left[\mathrm{OC}\left(\mathrm{O}^{i} \mathrm{Pr}\right)=\mathrm{CMe}_{2}\right]_{2} \quad\left(2, \mathrm{Cp}=\eta^{5}\right.$-cyclopentadienyl; Flu $=\eta^{\mathrm{n}}$-fluorenyl $), \quad\left[\mathrm{Ph}_{2} \mathrm{C}(\mathrm{Cp})(\mathrm{Flu})\right] \mathrm{Zr}$ $\left[\mathrm{OC}\left(\mathrm{O}^{i} \mathrm{Pr}\right)=\mathrm{CMe}_{2}\right]_{2} \quad(\mathbf{3})$, and $\left[\mathrm{Ph}_{2} \mathrm{C}(\mathrm{Cp})(\mathrm{Flu})\right] \mathrm{ZrMe}\left[\mathrm{OC}\left(\mathrm{O}^{i} \mathrm{Pr}\right)=\mathrm{CMe}_{2}\right]$ (4) can be readily activated with either $\left[\mathrm{Ph}_{3} \mathrm{C}\right]\left[\mathrm{B}\left(\mathrm{C}_{6} \mathrm{~F}_{5}\right)_{4}\right]$ (via hydride abstraction, followed by Michael addition), $\mathrm{B}\left(\mathrm{C}_{6} \mathrm{~F}_{5}\right)_{3}$ or THF $\cdot \mathrm{B}\left(\mathrm{C}_{6} \mathrm{~F}_{5}\right)_{3}$ (via methide abstraction), to generate the corresponding cationic complexes (catalysts) $\mathbf{2}^{+}\left[\mathrm{B}\left(\mathrm{C}_{6} \mathrm{~F}_{5}\right)_{4}\right]^{-}, \mathbf{3}^{+}\left[\mathrm{B}\left(\mathrm{C}_{6} \mathrm{~F}_{5}\right)_{4}\right]^{-}, \mathbf{4}^{+}\left[\mathrm{MeB}\left(\mathrm{C}_{6} \mathrm{~F}_{5}\right)_{3}\right]^{-}$, and $\mathbf{4}^{+}(\mathrm{THF})\left[\mathrm{MeB}\left(\mathrm{C}_{6} \mathrm{~F}_{5}\right)_{3}\right]^{-}$(5, Scheme 1), respectively. ${ }^{26}$ Such cationic complexes have been shown to promote rapid and syndiospecific polymerization of MMA at ambient temperature to produce highly syndiotactic st-PMMA with syndiotacticity up to $94 \% \mathrm{rr}$, proceeding through a monometallic, catalyst-site-controlled coordination-addition polymerization mechanism via eight-membered-ring ester enolate intermediates. ${ }^{26}$ Accordingly, $\mathbf{2}^{+}\left[\mathrm{B}\left(\mathrm{C}_{6} \mathrm{~F}_{5}\right)_{4}\right]^{-}$, 
$\mathbf{3}^{+}\left[\mathrm{B}\left(\mathrm{C}_{6} \mathrm{~F}_{5}\right)_{4}\right]^{-}, \mathbf{4}^{+}\left[\mathrm{MeB}\left(\mathrm{C}_{6} \mathrm{~F}_{5}\right)_{3}\right]^{-}$(generated by in-reactor activation), and $\mathbf{5}$ (generated by pre-activation) were employed for the current investigation into the polymerization of the three representative polar divinyl monomers, AMA, vinyl methacrylate (VMA), and $N, N$-diallyl acrylamide (DAA), aiming to achieve chemoselective and syndiospecific polymerization of such monomers and thus produce the corresponding highly syndiotactic polar vinyl polymers carrying a pendant $\mathrm{C}=\mathrm{C}$ bond in every repeat unit (Scheme 1).
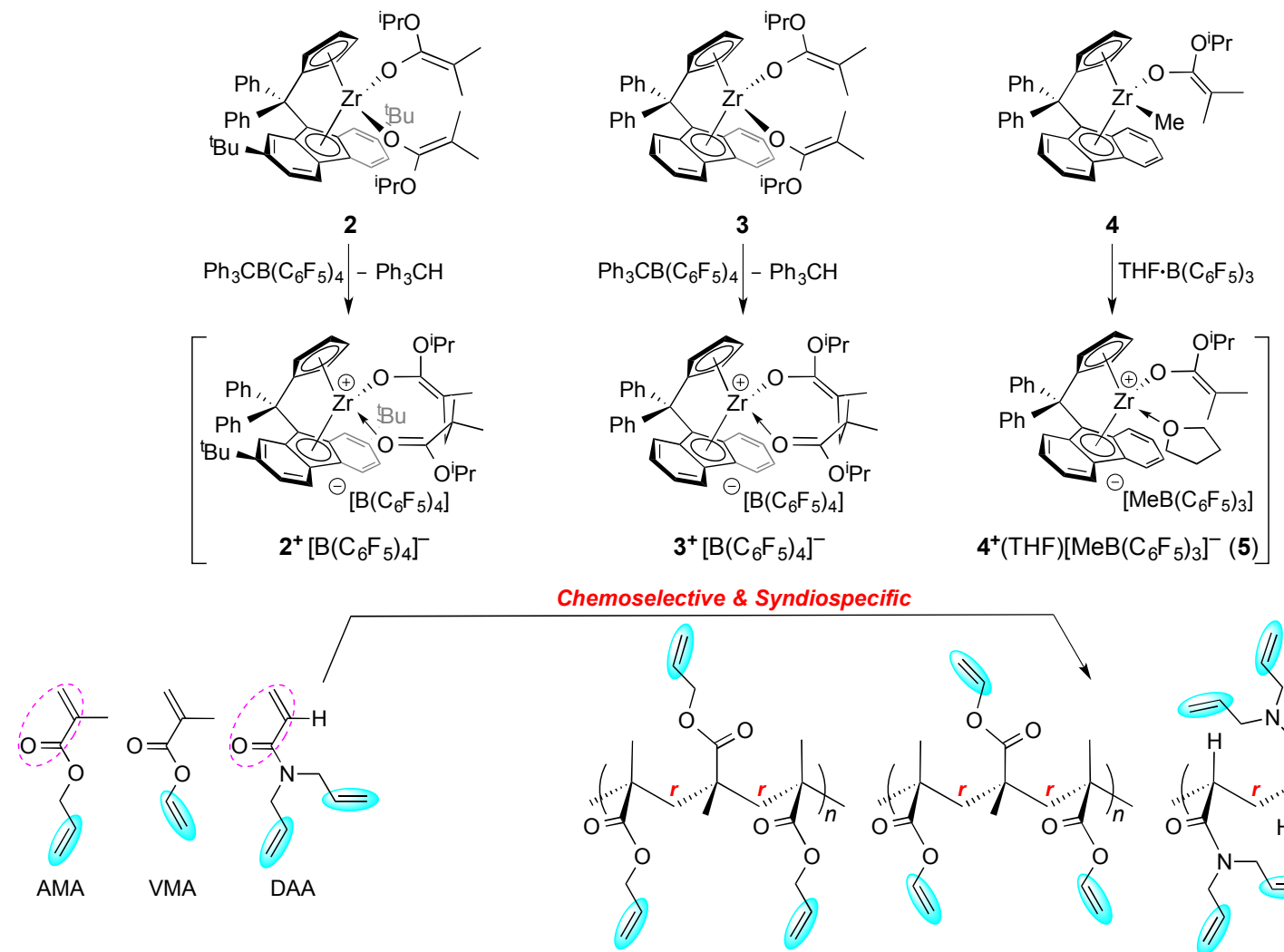

st-PAMA
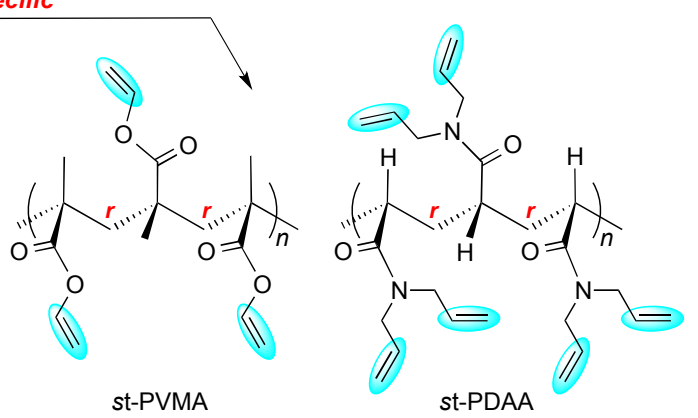

Scheme 1. Chemoselective and syndiospecific polymerization of polar divinyl monomers as well as structures of monomers, catalysts, and polymers involved in this study.

Selected results for the polymerization of the three representative polar divinyl monomers by precatalysts 2-4 are summarized in Table 1. At the outset, control runs showed that neither the neutral precatalyst nor the activator itself exhibited any activity toward such monomers. In contrast, cationic 
complexes $\mathbf{2}^{+}\left[\mathrm{B}\left(\mathrm{C}_{6} \mathrm{~F}_{5}\right)_{4}\right]^{-}, \quad \mathbf{3}^{+}\left[\mathrm{B}\left(\mathrm{C}_{6} \mathrm{~F}_{5}\right)_{4}\right]^{-}, \quad$ and $\mathbf{4}^{+}\left[\mathrm{MeB}\left(\mathrm{C}_{6} \mathrm{~F}_{5}\right)_{3}\right]^{-}$, derived from activation with $\left[\mathrm{Ph}_{3} \mathrm{C}\right]\left[\mathrm{B}\left(\mathrm{C}_{6} \mathrm{~F}_{5}\right)_{4}\right]$ (for bis-enolate precatalysts 2 and $\mathbf{3}$ ) or $\mathrm{B}\left(\mathrm{C}_{6} \mathrm{~F}_{5}\right)_{3}$ (for mono-enolate precatalyst 4 ), are highly active, quantitatively chemoselective, and also syndiospecific for polymerizations of such polar divinyl monomers at ambient temperature. Starting with the AMA polymerization in $\mathrm{CH}_{2} \mathrm{Cl}_{2}$ at $25{ }^{\circ} \mathrm{C}$, $3^{+}\left[\mathrm{B}\left(\mathrm{C}_{6} \mathrm{~F}_{5}\right)_{4}\right]^{-}(0.5$ mol\% loading $)$ afforded st-PAMA with a high syndiotacticity of $[r r]=92.4 \%$ and perfect chemoselectivity (Figure S2), but achieved a maximum monomer conversion of only 55\% in $1 \mathrm{~h}$ (run 2). Cationic complex $\mathbf{4}^{+}\left[\mathrm{MeB}\left(\mathrm{C}_{6} \mathrm{~F}_{5}\right)_{3}\right]^{-}$performed similarly (run 3 vs. 2). Interestingly, $\mathbf{2}^{+}\left[\mathrm{B}\left(\mathrm{C}_{6} \mathrm{~F}_{5}\right)_{4}\right]^{-}$, the more electron-rich and sterically encumbered catalyst with two substituted tert-butyl groups on the Flu ring, achieved a much higher monomer conversion of $92.7 \%$ and thus a higher molecular weight polymer $\left(M_{\mathrm{n}}=55.3 \mathrm{~kg} / \mathrm{mol}, Ð=1.33\right)$, but it produced $s t$-PAMA with a lower syndiotacticity of $[r r]=$ $87.9 \%$ (run 1). The isolated st-PAMA $\left(M_{\mathrm{n}}=35.0 \mathrm{~kg} / \mathrm{mol},[\mathrm{rr}]=92 \%\right.$, run 2$)$ is soluble in common organic solvents and exhibited a glass transition temperature $\left(T_{\mathrm{g}}\right)$ at $54{ }^{\circ} \mathrm{C}$, as measured by DSC, which is considerably higher than the counterpart it-PAMA $\left(-13{ }^{\circ} \mathrm{C}\right.$ to $0{ }^{\circ} \mathrm{C}$, in the order of increasing $\left.M_{\mathrm{n}}\right) \cdot{ }^{15} \mathrm{~A}$ thermal crosslinking exothermic peak with an onset temperature and a peak maximum of $142{ }^{\circ} \mathrm{C}$ and $>200^{\circ} \mathrm{C}$, respectively, was also observed on the DSC curve.

Table 1. Polymerization of polar divinyl monomers (M) by precatalysts $\mathbf{2 - 4}{ }^{a}$

\begin{tabular}{cccccccccccc}
\hline $\begin{array}{c}\text { run } \\
\text { no. }\end{array}$ & $\mathrm{M}$ & $\begin{array}{c}\text { Pre- } \\
\text { cat. }\end{array}$ & Activator & $\begin{array}{c}\text { Temp } \\
\left({ }^{\circ} \mathrm{C}\right)\end{array}$ & $\begin{array}{c}\text { Time } \\
(\mathrm{min})\end{array}$ & $\begin{array}{c}\text { conv. } \\
(\%)\end{array}$ & $\begin{array}{c}M_{\mathrm{n}}{ }^{c} \\
(\mathrm{~kg} / \mathrm{mol})\end{array}$ & $\begin{array}{c}D^{c} \\
\left(M_{\mathrm{w}} / \mathrm{M}_{\mathrm{n}}\right)\end{array}$ & $\begin{array}{c}{[\mathrm{rr}]^{d}} \\
(\%)\end{array}$ & $\begin{array}{c}{[\mathrm{mr}]^{d}} \\
(\%)\end{array}$ & $\begin{array}{c}{[\mathrm{mm}]^{d}} \\
(\%)\end{array}$ \\
\hline 1 & AMA & $\mathbf{2}$ & {$\left[\mathrm{Ph}_{3} \mathrm{C}\right][\mathrm{B}]$} & 25 & 180 & 92.7 & 55.3 & 1.33 & 87.9 & 10.6 & 1.5 \\
2 & $\mathrm{AMA}$ & $\mathbf{3}$ & {$\left[\mathrm{Ph}_{3} \mathrm{C}\right][\mathrm{B}]$} & 25 & 60 & 55.1 & 35.0 & 1.56 & 92.4 & 6.0 & 1.6 \\
3 & $\mathrm{AMA}$ & $\mathbf{4}$ & {$[\mathrm{B}]$} & 25 & 60 & 53.0 & 24.5 & 1.32 & 90.7 & 7.4 & 1.9 \\
\hline 4 & $\mathrm{VMA}$ & $\mathbf{2}$ & {$\left[\mathrm{Ph}_{3} \mathrm{C}\right][\mathrm{B}]$} & 25 & 60 & 96.2 & 42.9 & 1.40 & 87.0 & 10.5 & 2.5 \\
5 & $\mathrm{VMA}$ & $\mathbf{3}$ & {$\left[\mathrm{Ph}_{3} \mathrm{C}\right][\mathrm{B}]$} & 25 & 30 & 98.3 & 42.5 & 1.38 & 92.4 & 7.0 & 0.6 \\
6 & $\mathrm{VMA}$ & $\mathbf{4}$ & {$[\mathrm{B}]$} & 25 & 30 & 98.5 & 41.2 & 1.36 & 93.0 & 6.4 & 0.6 \\
7 & $\mathrm{VMA}$ & $\mathbf{4}$ & {$[\mathrm{B}] \cdot \mathrm{THF}$} & 25 & 10 & 100 & 42.5 & 1.36 & 93.5 & 6.1 & 0.4 \\
8 & $\mathrm{VMA}$ & $\mathbf{3}$ & {$\left[\mathrm{Ph}{ }_{3} \mathrm{C}\right][\mathrm{B}]$} & 0 & 30 & 100 & 86.7 & 1.21 & 95.7 & 2.9 & 1.4 \\
9 & $\mathrm{VMA}$ & $\mathbf{4}$ & {$[\mathrm{B}] \cdot \mathrm{THF}$} & 0 & 30 & 97.0 & 98.3 & 1.17 & 94.8 & 3.5 & 1.7 \\
\hline 10 & $\mathrm{DAA}$ & $\mathbf{3}$ & {$[\mathrm{Ph}$ C $][\mathrm{B}]$} & 25 & 10 & 89.0 & 47.5 & 1.34 & $>99$ & - & - \\
11 & $\mathrm{DAA}$ & $\mathbf{4}$ & {$[\mathrm{B}] \cdot \mathrm{THF}$} & 25 & 10 & 94.5 & 42.9 & 1.29 & $>99$ & - & - \\
\hline
\end{tabular}


${ }^{a}$ Conditions: activator $\left[\mathrm{Ph}_{3} \mathrm{C}\right][\mathrm{B}]=\left[\mathrm{Ph}_{3} \mathrm{C}\right]\left[\mathrm{B}\left(\mathrm{C}_{6} \mathrm{~F}_{5}\right)_{4}\right],[\mathrm{B}]=\mathrm{B}\left(\mathrm{C}_{6} \mathrm{~F}_{5}\right)_{3}$; solvent $(3.0 \mathrm{~mL}) \mathrm{CH}_{2} \mathrm{Cl}_{2}$ for runs 1-9, toluene for runs 10 and 11; $[\mathrm{M}] /[\mathrm{cat}]=200$; pre-activation method (pre-mixing of pre-catalyst with activator, followed by addition of monomer), except for runs \#3 and \#6 where the in-reactor activation method was used (pre-mixing of monomer with activator, followed by addition of pre-catalyst). ${ }^{b}$ Monomer (M) conversion measured by ${ }^{1} \mathrm{H} \mathrm{NMR} .{ }^{c}$ Number-average molecular weight $\left(M_{\mathrm{n}}\right)$ and dispersity $(\nexists)$ determined by gel-permeation chromatography (GPC) relative to PMMA standards. ${ }^{d}$ Tacticity measured by ${ }^{1} \mathrm{H}$ or ${ }^{13} \mathrm{C}$ NMR in $\mathrm{CDCl}_{3}$.

Moving to VMA polymerization, all three $C_{\mathrm{s}}$-ligated catalysts are perfectly chemoselective and highly syndiospecific. Again, the two catalysts without the tert-butyl substitution, $3^{+}\left[\mathrm{B}\left(\mathrm{C}_{6} \mathrm{~F}_{5}\right)_{4}\right]^{-}$and $4^{+}\left[\mathrm{MeB}\left(\mathrm{C}_{6} \mathrm{~F}_{5}\right)_{3}\right]^{-}$, exhibited similar polymerization characteristics (run 5 vs. 6), including high activity ( $>98 \%$ conversion in $30 \mathrm{~min})$, medium molecular weight $\left(M_{\mathrm{n}}=41.2-42.5 \mathrm{~kg} / \mathrm{mol}\right)$, medium dispersity $(\nexists$ $=1.36-1.38)$, and high syndiotacticity $([r r]=92.4 \%$ and $93.0 \%)$. The polymerization by cation $5\{=$ $\mathbf{4}(\mathrm{THF})^{+}\left[\mathrm{MeB}\left(\mathrm{C}_{6} \mathrm{~F}_{5}\right)_{3}\right]^{-}$, generated from the reaction of $\mathbf{4}+\mathrm{THF} \cdot \mathrm{B}\left(\mathrm{C}_{6} \mathrm{~F}_{5}\right)_{3}$, Scheme 1$\}$ was even more rapid, achieving 100\% monomer conversion in only 10 min without signs of gel formation and also producing st-PVMA with a high syndiotacticity of $[r r]=93.5 \%$ (run 7 ). When the polymerization was carried out at $0{ }^{\circ} \mathrm{C}$, the molecular weight of the resulting polymer was much higher and the dispersity became narrower, while still achieving quantitative or near quantitative conversion: $M_{\mathrm{n}}=86.7 \mathrm{~kg} / \mathrm{mol}, Ð$ $=1.21,[r r]=95.7 \%$ by $3^{+}\left[\mathrm{B}\left(\mathrm{C}_{6} \mathrm{~F}_{5}\right)_{4}\right]^{-}$(run 8$) ; M_{\mathrm{n}}=98.3 \mathrm{~kg} / \mathrm{mol}, Ð=1.17,[r r]=94.8 \%$ by $\mathbf{5}$ (run 9 ). The chemoselectivity of the VMA polymerization is also perfect, as revealed by complete disappearance of the methacrylic $=\mathrm{CH}_{2}$ proton signals at $\delta 6.23$ and $5.68 \mathrm{ppm}$ and complete retention of the pendant vinyl group $-\mathrm{CH}=\mathrm{CH}_{2}$ proton signals centered at $\delta 7.14,4.91$, and $4.63 \mathrm{ppm}$ (Figure 2), indicating that the polymerization proceeded exclusively through conjugate addition across the methacrylic double bond. Significantly, analysis of the triad stereoerrors of the resulting st-PVMA gave $2[\mathrm{~mm}] /[\mathrm{mr}] \sim 1(0.97$ for both runs 8 and 9), indicative of an enantiomorphic-site controlled mechanism. Furthermore, the ${ }^{13} \mathrm{C}$ NMR spectrum of the polymer in the $\mathrm{C}=\mathrm{O}$ pentad ( $r r r r)$ region provided collaborative evidence for the formation of the highly syndiotactic st-PVMA (Figure 3). DSC analysis of the highly syndiotactic stPVMA showed a $T_{\mathrm{g}}$ of $\sim 100{ }^{\circ} \mathrm{C}$, which is considerably higher than at-PVMA $\left(44-49^{\circ} \mathrm{C}\right),{ }^{15}$ as well as a thermal crosslinking exothermic peak with an onset temperature and a peak maximum of $153{ }^{\circ} \mathrm{C}$ and 184 
${ }^{\circ} \mathrm{C}$, respectively. We also examined the degree of the polymerization control over molecular weight by varying the $[\mathrm{VMA}] /[5]$ ratio from 100 to 900 (0.11 mol\% catalyst loading) in $\mathrm{CH}_{2} \mathrm{Cl}_{2}$ at ambient temperature, all of which runs proceeded to high conversions without signs of gel formation. The $M_{\mathrm{n}}$ value of the resulting st-PVMA increased linearly $\left(\mathrm{R}^{2}=0.992\right)$ from $29.6 \mathrm{~kg} / \mathrm{mol}(\nexists=1.28)$ to 164 $\mathrm{kg} / \mathrm{mol}(\bigoplus=1.48$, Figure 4) as the [VMA]/[5] ratio was increased from 100 to 900 , showing the ability of this polymerization system to control the resulting polymer molecular weight while maintaining the relatively low dispersity.
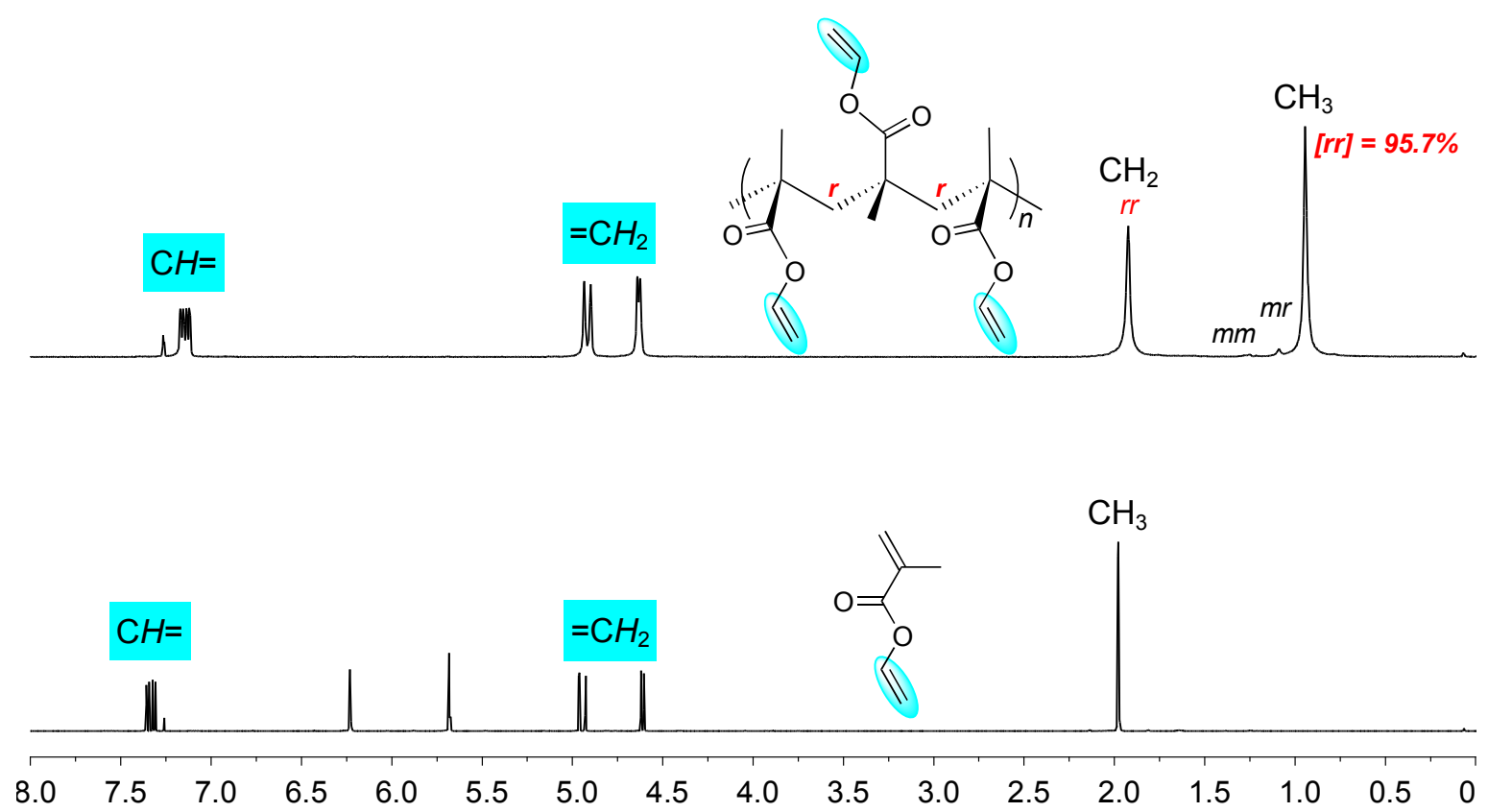

Figure 2. Overlay of ${ }^{1} \mathrm{H} \mathrm{NMR}\left(\mathrm{CDCl}_{3}, 25^{\circ} \mathrm{C}\right)$ spectra of VMA and st-PVMA. 

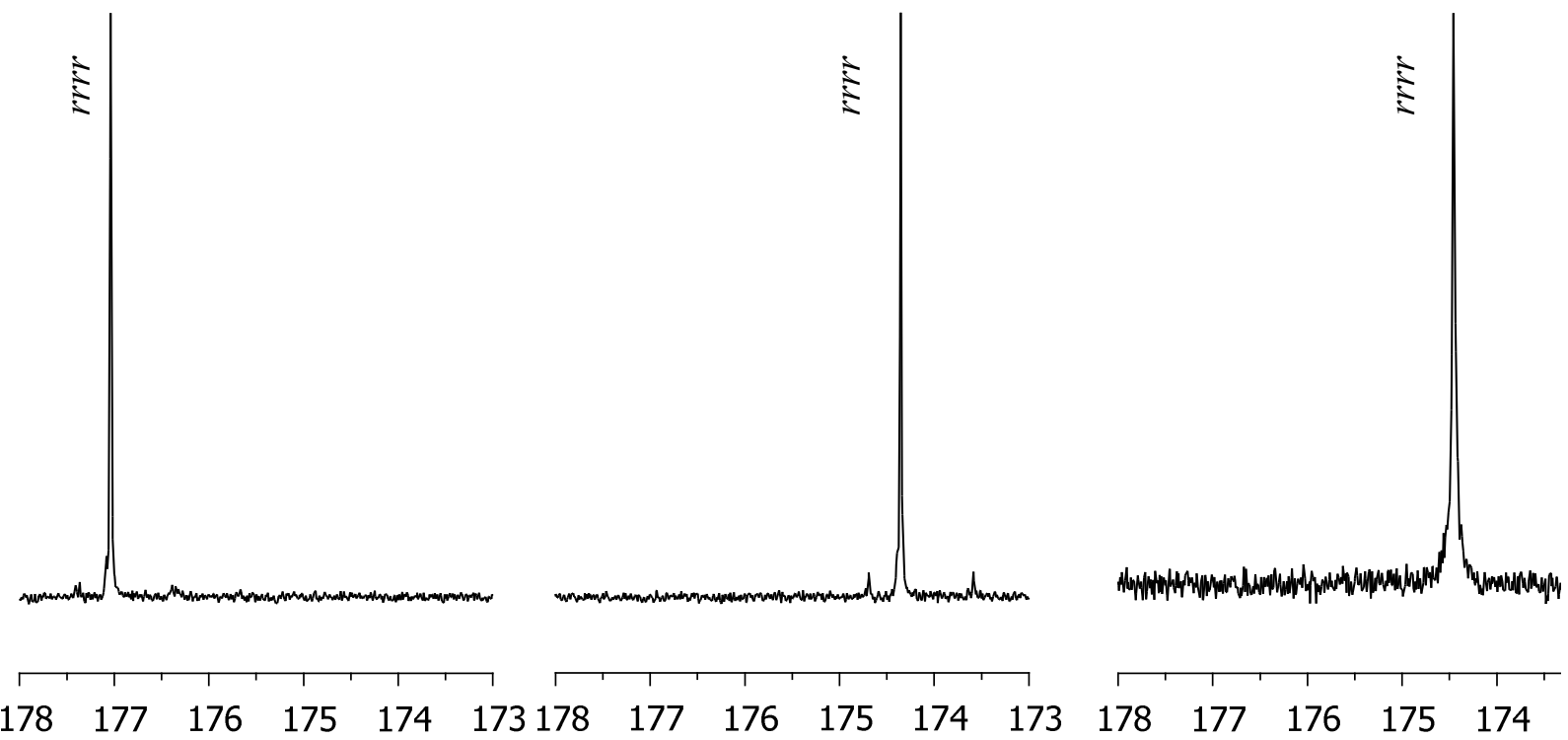

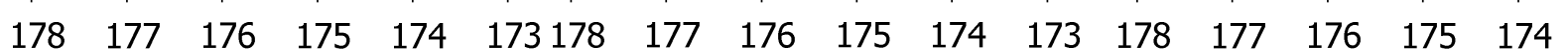

Figure 3. ${ }^{13} \mathrm{C}$ NMR spectra $\left(\mathrm{CDCl}_{3}, 50{ }^{\circ} \mathrm{C}\right)$ showing the $\mathrm{C}=\mathrm{O}$ pentad (rrrr) region of st-AMA (left, run 2), st-PVMA (center, run 8) and st-PDAA (right, run 10).

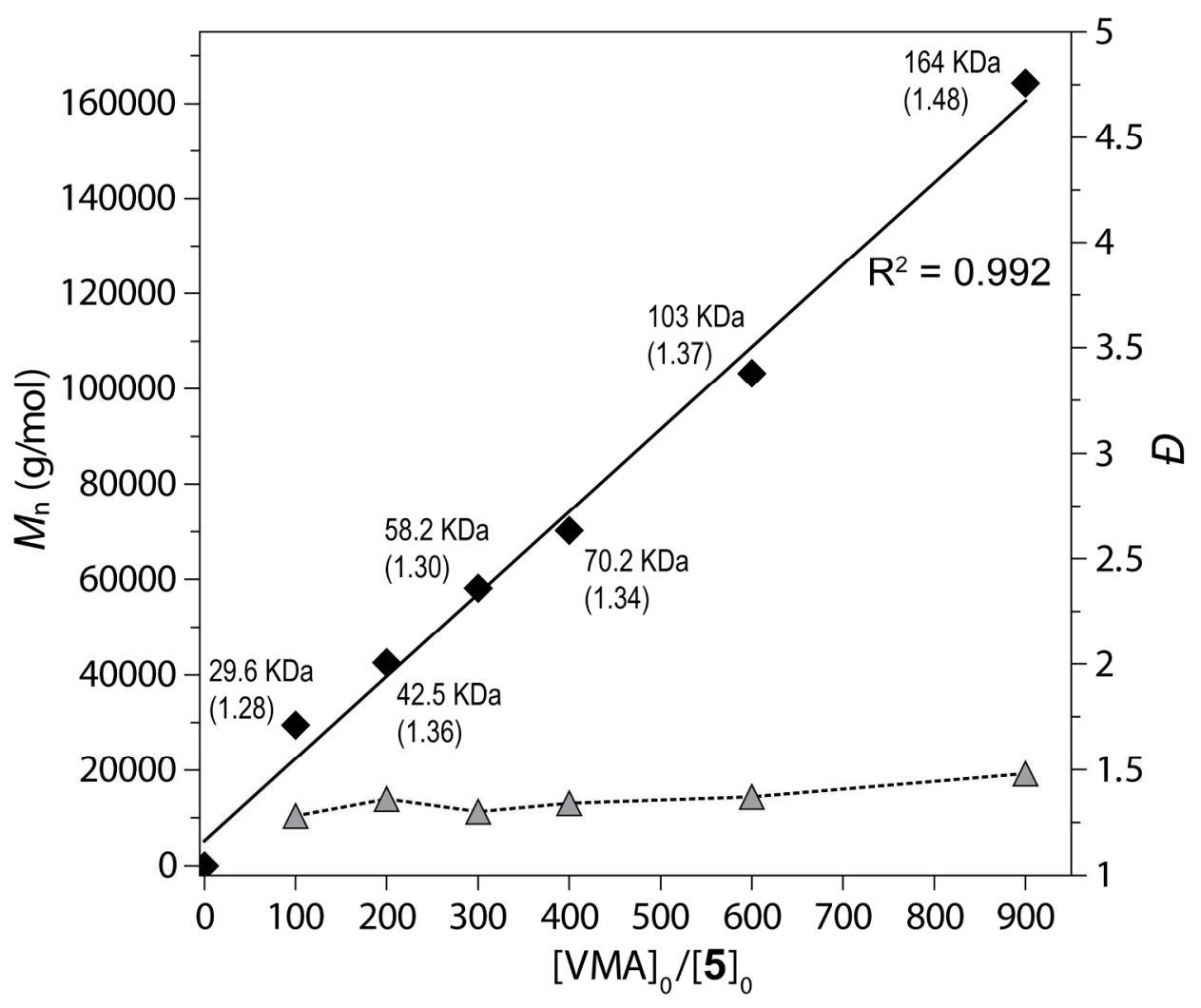


Figure 4. Plots of $M_{\mathrm{n}}(\mathrm{kg} / \mathrm{mol}$ or $\mathrm{kDa})$ and $Ð$ (shown in parenthesis) of $s t$-PVMA produced by 5 vs. $[\mathrm{VMA}]_{0} /[\mathbf{5}]_{0}$ ratio $\left(\mathrm{CH}_{2} \mathrm{Cl}_{2}, 23^{\circ} \mathrm{C}\right)$.

The chemoselectivity and stereospecificity of $\mathbf{3}^{+}\left[\mathrm{B}\left(\mathrm{C}_{6} \mathrm{~F}_{5}\right)_{4}\right]^{-}$and $\mathbf{5}$ toward the polymerization of DAA were also carefully examined. Remarkably, this polymerization not only was rapid, achieving $89.0 \%$ (run 10) and $94.5 \%$ (run 11) conversions in $10 \mathrm{~min}$, it also exhibited both quantitative chemoselectivity (Figure S3) and syndiospecificity ([rr] > 99\%, Figure 3). DSC analysis of the highly syndiotactic stPDAA showed a $T_{\mathrm{g}}$ of $35.8{ }^{\circ} \mathrm{C}$ as well as a thermal crosslinking exothermic peak with an onset temperature and a peak maximum of $216{ }^{\circ} \mathrm{C}$ and $290{ }^{\circ} \mathrm{C}$, respectively. Worth noting also is that st-PDAA is soluble in common solvents of a wide polarity range, including $\mathrm{MeOH}, \mathrm{DMF}$, THF, acetone, $\mathrm{CHCl}_{3}$, $\mathrm{Et}_{2} \mathrm{O}$, and toluene, whereas it-PDAA is found soluble only in limited solvents such as $\mathrm{CHCl}_{3}$ and $\mathrm{CH}_{2} \mathrm{Cl}_{2}$. In comparison, the initiator efficiency $\left(I^{*}\right)$, calculated as $I^{*}=M_{\mathrm{n}}($ calcd $) / M_{\mathrm{n}}(\operatorname{exptl})$, where $M_{\mathrm{n}}($ calcd $)=$ $\mathrm{MW}(\mathrm{M}) \times[\mathrm{M}]_{0} /[\mathrm{Zr}]_{0} \times$ conversion $\%+$ MW of chain-end groups, was in the range of $43-55 \%$ for AMA polymerization at RT, 51-54 \% for VMA polymerization at RT, and 57-67 \% for DAA polymerization at RT.

Mechanism of Polymerization. Next, we examined the kinetics of VMA polymerization by catalyst $\mathbf{5}$, revealing the polymerization is first-order with respect to monomer concentration [VMA] for all the six $[\mathrm{VMA}]_{0} /[5]_{0}$ ratios investigated (150 to 500, Figure 5). A double logarithm plot (Figure 6 ) of the apparent rate constants $\left(k_{\text {app }}\right)$, obtained from the slopes of the best-fit lines to the plots of $\ln \left([\mathrm{VMA}]_{0} /[\mathrm{VMA}]_{t}\right)$ vs. time, as a function of $\ln \left([5]_{0}\right)$, was fit to a straight line $\left(\mathrm{R}^{2}=0.986\right)$ with a slope of 1.1. Thus, the kinetic order with respect to [5], given by the slope of $\sim 1$, reveals that the propagation is also first order in catalyst concentration. These results indicate that the resting state in the proposed monometallic propagation "catalytic" cycle (Scheme 2) is the cyclic ester enolate B, which was structurally modeled by the isolated cationic cyclic ester enolate complex $\mathbf{6}$ (vide infra), and that associative displacement of the coordinated ester group by incoming monomer to regenerate the active 
species A (structurally modeled by complex $\mathbf{5}$ ) is the rate-determining step (i.e., $\mathbf{B} \rightarrow \mathbf{A}$, Scheme 2). These key features of the mechanism are the same as those already established for the coordinationaddition polymerization of alkyl methacrylates. ${ }^{3 b, 13,26}$

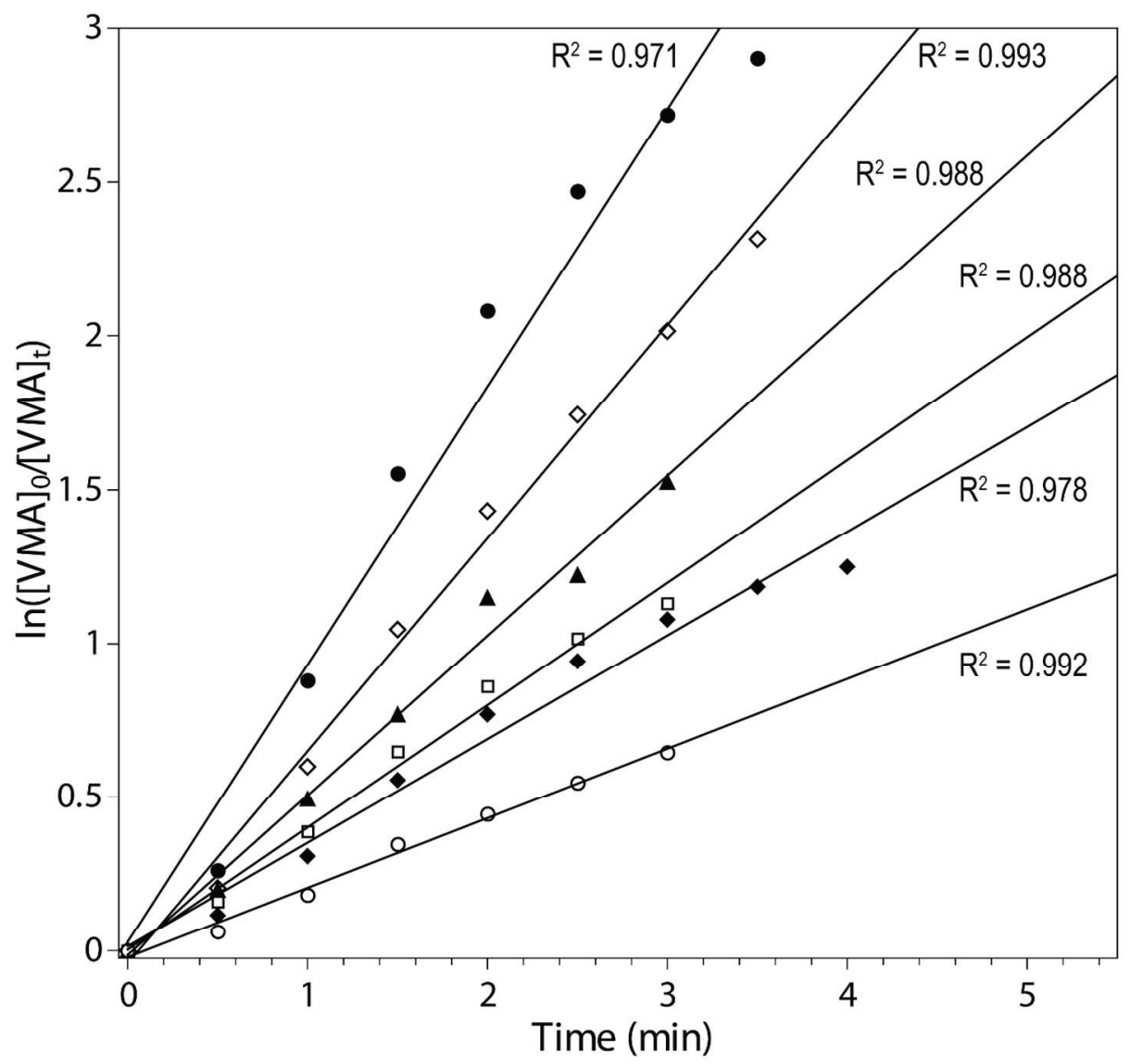

Figure 5. Semilogarithmic plots of $\ln \left\{[\mathrm{VMA}]_{0} /[\mathrm{VMA}]_{t}\right\}$ vs. time for the polymerization of VMA by 5 in $\mathrm{CH}_{2} \mathrm{Cl}_{2}$ at $23{ }^{\circ} \mathrm{C}$. Conditions: $[\mathrm{VMA}]_{0}=0.832 \mathrm{M} ;[\mathbf{5}]_{0}=5.55 \mathrm{mM}(\bullet), 4.16 \mathrm{mM}(\diamond), 3.33 \mathrm{mM}(\boldsymbol{\Delta}), 2.77$ $\mathrm{mM}(\square), 2.07 \mathrm{mM}(\diamond), 1.66 \mathrm{mM}(\circ)$. 


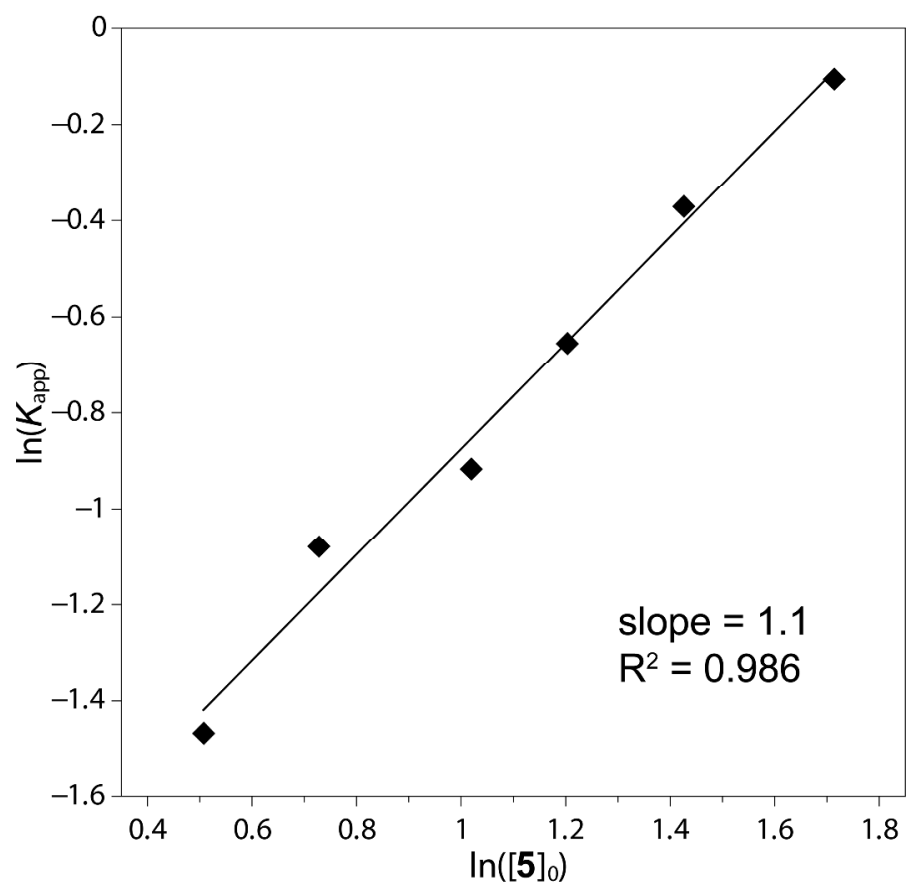

Figure 6. Plot of $\ln \left(k_{\text {app }}\right)$ vs. $\ln \left([5]_{0}\right)$ for the VMA polymerization by 5 in $\mathrm{CH}_{2} \mathrm{Cl}_{2}$ at $23{ }^{\circ} \mathrm{C}$.

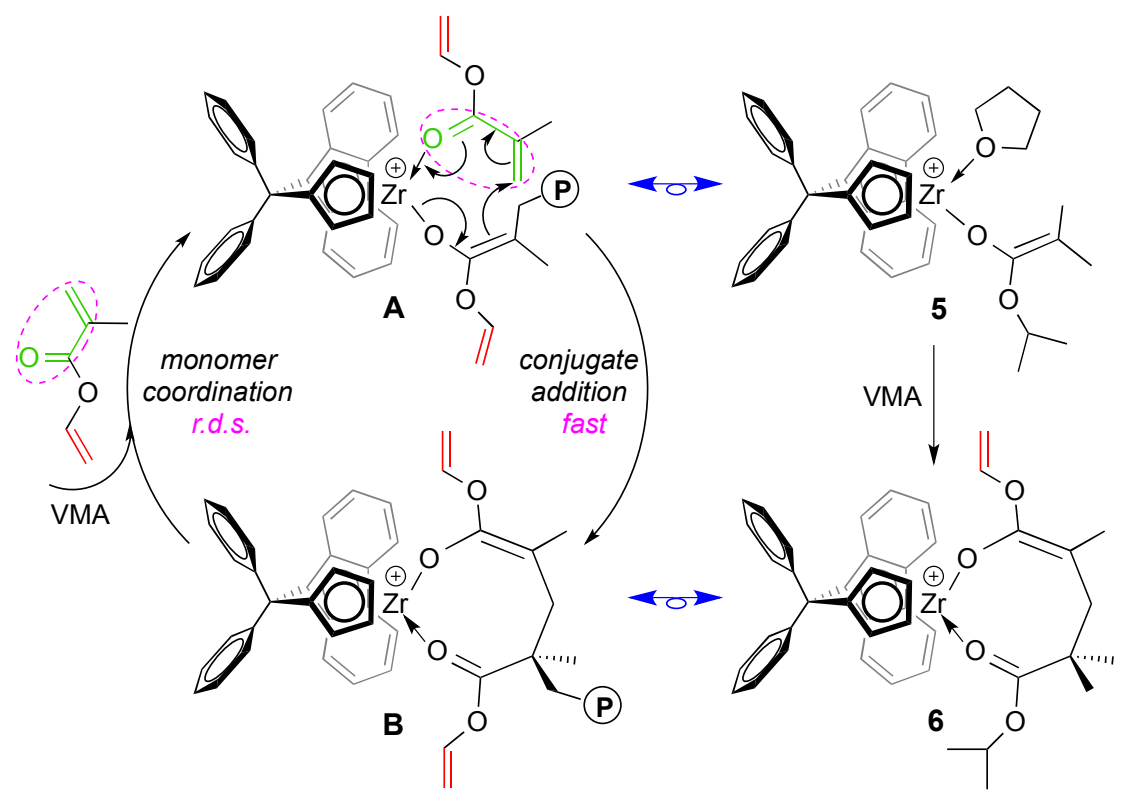

Scheme 2. Proposed mechanism (propagation "catalytic" cycle) for the chemoselective and syndiospecific polymerization of VMA as well as the structures of $\mathbf{5}$ and $\mathbf{6}$ as synthetic structural models for active species $\mathbf{A}$ and resting state chelate $\mathbf{B}$, respectively. 
To provide further evidence to support the mechanism outlined in Scheme 2, cation 5 was reacted with 1 equiv of VMA to cleanly generate the corresponding single-monomer-addition product, the eightmembered metallacycle ${ }^{27}$ resting intermediate $\left\{\left[\mathrm{Ph}_{2} \mathrm{C}(\mathrm{Cp})(\mathrm{Flu})\right] \mathrm{Zr}\left[\mathrm{OC}\left(\mathrm{OCH}=\mathrm{CH}_{2}\right)=\mathrm{CMeCH}_{2} \mathrm{C}\left(\mathrm{Me}_{2}\right)\right.\right.$ $\left.\left.\mathrm{C}\left(\mathrm{O}^{i} \mathrm{Pr}\right)=\mathrm{O}\right]\right\}^{+}\left[\mathrm{MeB}\left(\mathrm{C}_{6} \mathrm{~F}_{5}\right)_{3}\right]^{-}$(6) (Figure 7). This intermediate can also be generated and isolated in $>91 \%$ yield via the 1:1 ratio reaction of the pre-catalyst 4 with the borane-monomer adduct $\mathrm{VMA} \cdot \mathrm{B}\left(\mathrm{C}_{6} \mathrm{~F}_{5}\right)_{3}(\mathrm{see}$ the SI for procedures and characterizations). Likewise, the metallacycle corresponding to the first AMA addition intermediate $\quad\left\{\left[\mathrm{Ph}_{2} \mathrm{C}(\mathrm{Cp})(\mathrm{Flu})\right] \mathrm{Zr}\left[\mathrm{OC}\left(\mathrm{OCH}_{2} \mathrm{CH}=\mathrm{CH}_{2}\right)=\mathrm{CMeCH}_{2} \mathrm{C}\left(\mathrm{Me}_{2}\right) \mathrm{C}\left(\mathrm{O}^{i} \mathrm{Pr}\right)=\mathrm{O}\right]\right\}^{+}$ $\left[\mathrm{MeB}\left(\mathrm{C}_{6} \mathrm{~F}_{5}\right)_{3}\right]^{-}$(7) was generated in the similar fashion (see the SI and Figure S4). The successful generation and isolation of the first-monomer-addition product $\mathbf{6}$, serving as the structural model of the resting intermediate $\mathbf{B}$, implies that the monomer addition is fast relative to the monomer coordination in the propagation "catalytic" cycle depicted in Scheme 2 (otherwise, only polymers or oligomers, plus the unreacted 5 or $\mathbf{4}$, would be formed). Importantly, addition of excess of VMA to a solution of $\mathbf{6}$ brought about rapid polymerization of VMA into st-PVMA, thereby confirming cation $\mathbf{6}$ as the resting intermediate of the catalytic cycle by this kinetic competence check. Overall, all the experimental evidence to date is consistent with the polymerization mechanism depicted in Scheme 2.

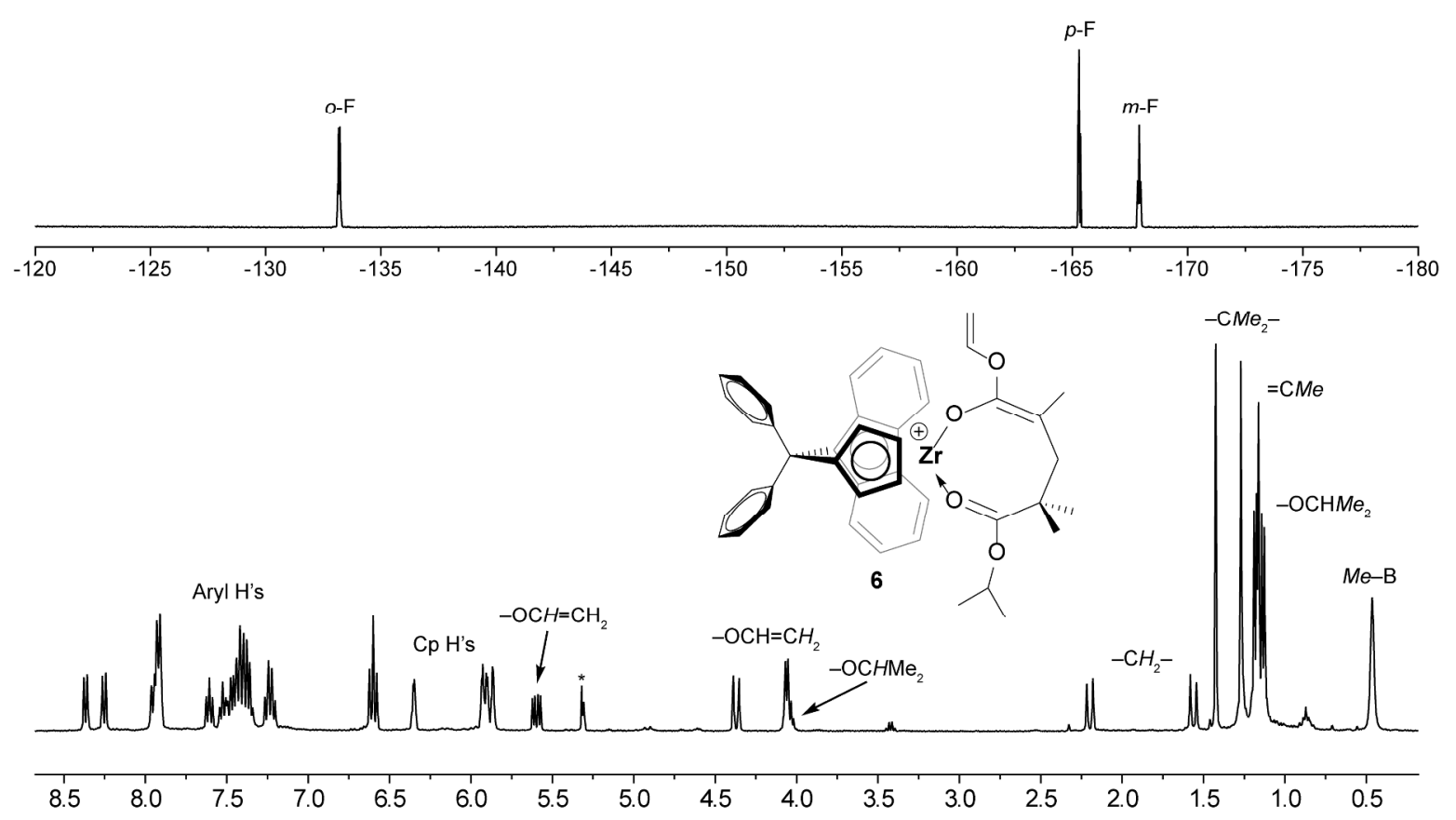


Figure 7. ${ }^{19} \mathrm{~F}$ NMR (top) and ${ }^{1} \mathrm{H}$ (bottom) spectra $\left(\mathrm{CD}_{2} \mathrm{Cl}_{2}, 25{ }^{\circ} \mathrm{C}\right.$, residual NMR labeled as *) of the isolated cationic complex 6. Anion $\left[\mathrm{MeB}\left(\mathrm{C}_{6} \mathrm{~F}_{5}\right)_{3}\right]^{-}$omitted for clarity.

Mechanism of Stereoselection. Next, we investigated the mechanism of stereoselection by a computation study via DFT calculations. This needed study was prompted by an interesting observation that, while the polymerizations of AMA and VMA by the $C_{2}$-ligated catalyst $\mathbf{1}$ were drastically different, leading to formation of highly isotactic PAMA with $[\mathrm{mm}]=95-97 \%$ and isotactic-biased PVMA with $[\mathrm{mm}]=51-53 \%$, respectively,${ }^{15}$ both polymerizations of AMA and VMA by $C_{\mathrm{s}}$-ligated catalysts afforded highly syndiotactic polymers, with even higher syndiotacticity of $[r r]=94-96 \%$ achieved for the VMA polymerization (vide supra). Thus, it is intriguing that the placement of the $\mathrm{sp}^{3}$-hybridized $\mathrm{CH}_{2}$ group between the ester oxygen atom and the $\mathrm{sp}^{2}$-hybridized vinyl moiety in the case of AMA substantially enhanced the isospecificity of the polymerization but had no effect on (or even slightly reduced) the syndiospecificity of the polymerization, relative to VMA without the $\mathrm{CH}_{2}$ group, highlighting the importance of the sterics and orientation of the ester OR group of the methacrylate monomer in the transition state (TS) structure that determines the stereospecificity of the metallocene-catalyzed polymerization. ${ }^{26 a, 28}$ Accordingly, DFT calculations were performed to provide a rationalization of the above experimentally observed high isospecificity in AMA polymerization and the low isospecificity in VMA polymerization by $C_{2}$-ligated catalyst 1 (EBI-Zr) system, as well as the high syndiospecificity in both AMA and VMA polymerizations with $C_{\mathrm{s}}$-ligated catalyst $5\left[\mathrm{Ph}_{2} \mathrm{C}(\mathrm{Cp})(\mathrm{Flu}) \mathrm{Zr}\right]$ system.

We calculated all the TSs for AMA and VMA additions involving the re and si prochiral faces of the growing chain by considering geometries where the pendant group of the monomer and of the chain are located on opposite sides (trans) or on the same side (cis) of the metallocene equatorial belt. In addition, for the $C_{2}$-symmetric EBI-Zr system, the $g^{+}$and $g^{-}$conformations of the metallocene bridge have been considered. ${ }^{28}$ In all the geometries a ${ }^{t} \mathrm{Bu}$ group was used to model the remaining of the growing chain. For the sake of simplicity, we anticipate that with the $(S, S)$-EBI-Zr based system all competitive 
geometries show a $g^{+}$conformation of the metallocene bridge. The favored TS involves the $s i$ face of the chain and shows a trans geometry whereas the cis geometry is favored for the competitive re-face addition, with both monomers. Finally, with the $(S)-\mathrm{Ph}_{2} \mathrm{C}(\mathrm{Cp}) \mathrm{Flu}-\mathrm{Zr}$ system a trans geometry is favored in both TSs. ${ }^{26 a, 28}$

The geometries and the corresponding free energy $\Delta G_{\text {Stereo }}(\mathrm{kcal} / \mathrm{mol}, \mathrm{DCM})$ of the competitive TSs are reported in Figure 8 for $\mathbf{1}$ and in Figure 9 for $\mathbf{5}$ with both monomers. Focusing on AMA addition, with 1 the TS involving the $s i$-face of the growing chain is favored by a $\Delta G_{\text {Stereo }}$ of $5.6 \mathrm{kcal} / \mathrm{mol}$ (Figure $8 \mathrm{a}$ vs. $8 \mathrm{~b})$. Competition is with addition of the re-face, which is disfavored by steric repulsion between the 6membered ring of the indenyl ligand and the -OR group of the growing chain. To alleviate this steric clash the pendant -OR group of the chain rotates away from the indenyl ligand resulting in a gauche conformation of the C1-C2-O3-C4 dihedral angle (Figure 8b). Differently, in the favored si-face addition TS the C1-C2-O3-C4 dihedral angle is much closer to the ideal trans value (Figure 8a). The high $\Delta G_{\text {Stereo }}$ of $5.6 \mathrm{kcal} / \mathrm{mol}$ is in qualitative agreement with the high isotacticity of the obtained PAMA.

a)

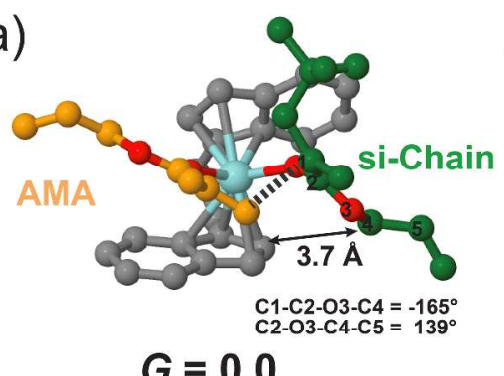

c)

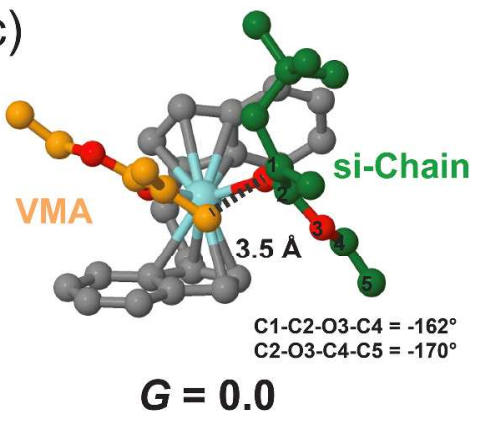

b)

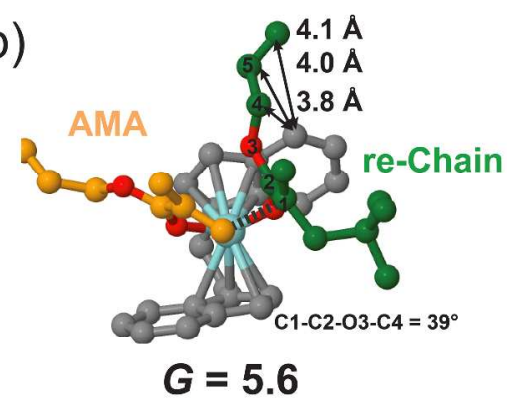

d)

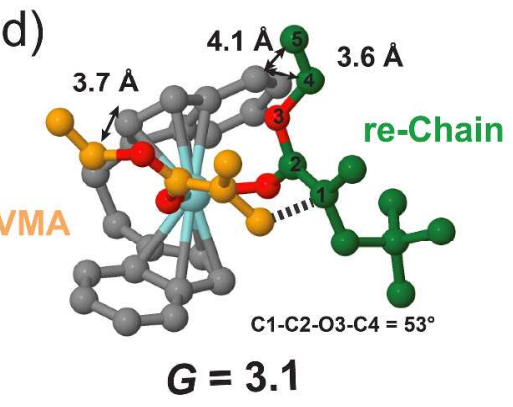


Figure 8. Transition state geometries for the competitive addition at the si and re face of the growing chain for AMA (a and b) and VMA (c and d), respectively, with $(S, S)$-EBI-Zr system (1). The free energies ( $\mathrm{kcal} / \mathrm{mol}, \mathrm{DCM})$ are relative to the TS involving the si face of the growing chain (a and $\mathbf{c})$. The dashed line indicates the emerging $\mathrm{C}-\mathrm{C}$ bonds.

The competitive TSs geometries associated with VMA addition are compared in Figures 8c and 8d. In this case, addition of the $s i$-face is favored by a $\Delta G_{\text {Stereo }}$ of $3.1 \mathrm{kcal} / \mathrm{mol}$ over addition of the $r e$-face. As for AMA, the TS for addition of the re-face is disfavored by steric interaction between the pendant group of the chain and the indenyl ligand, resulting in a less stable conformation assumed by the growing chain, with a $\mathrm{C} 1-\mathrm{C} 2-\mathrm{O} 3-\mathrm{C} 4$ dihedral angle of $53^{\circ}$ (Figure $8 \mathrm{~d}$ ). Although still rather large in absolute value, the $\Delta G_{\text {Stereo }}$ of $3.1 \mathrm{kcal} / \mathrm{mol}$ calculated for VMA is $2.5 \mathrm{kcal} / \mathrm{mol}$ lower than the $\Delta G_{\text {Stereo }}$ calculated for the AMA, in qualitative agreement with the observed much lower isotacticity of the produced PVMA. The lower stability of the favored si-face TS for VMA is responsible for the observed lower selectivity in the polymerization of VMA relative to AMA: the different nature of the ester carbon in the chain, $\mathrm{sp}^{2}$ for VMA $v s \mathrm{sp}^{3}$ for AMA, induces a different steric interaction between the chain and the metallocene skeleton, mainly in the favored si-face TSs (Figure 8a vs. 8c). In fact, despite the fact that the $s i$-chain is located in the open part of the catalyst, being away from from the 6-membered ring of the indenyl ligand, in the case of VMA the rigid $-\mathrm{O}-\mathrm{CH}=\mathrm{CH}_{2}$ group is forced to be close to the 5-membered ring of the ligand (see short distances reported in Figure 8c). Conversely, in the case of AMA, the sp ${ }^{3}$ ester carbon of the $-\mathrm{O}-\mathrm{CH}_{2}-\mathrm{CH}=\mathrm{CH}_{2}$ moiety allows the chain to rotate away from the 5-membered ring of the ligand, minimizing unfavorable interaction between the -OR group of the growing chain and the metallocene skeleton (compare the value of $139^{\circ}$ for the C2-O3-C4-C5 dihedral angle in the case of AMA vs. the value of $-170^{\circ}$ in the case of VMA in Figures $8 \mathrm{a}$ and 8c, respectively).

Moving to $C_{\mathrm{S}}$-ligated catalyst $\mathbf{5}$, with both monomers, the favored TS involves the $s i$-face of the chain, which is located in an open part of the space away from the fluorenyl moiety of the ligand (Figures 
9a and 9c). Steric interaction between the monomer and the metallocene skeleton can be observed for both AMA and VMA. The competitive re-face TSs are disfavored by steric interaction between the chain and the ligand (see the short distance in Figures $9 \mathrm{~b}$ and $9 \mathrm{~d}$ ). The rather similar $\Delta G_{\text {Stereo }}$ of $2.7 \mathrm{kcal} / \mathrm{mol}$ and $2.2 \mathrm{kcal} / \mathrm{mol}$, calculated for VMA and AMA, respectively, are in good agreement with the experimentally observed similar syndiotacticity of PVMA and PAMA (although the syndiotacticity of PVMA is somewhat higher than that of PAMA, vide supra).

a)

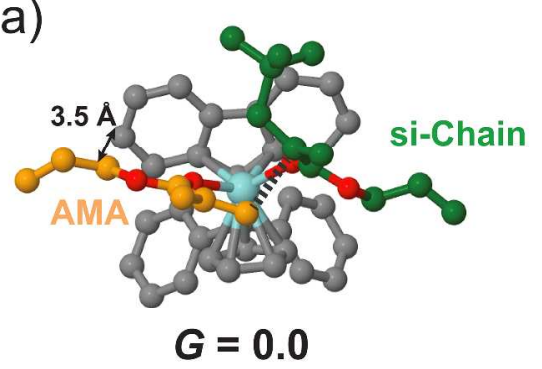

C)

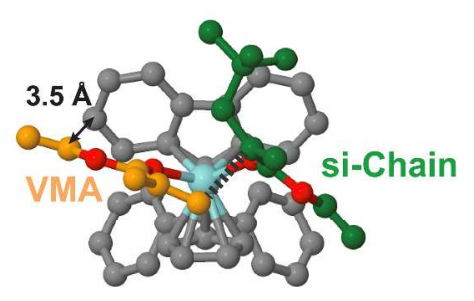

$G=0.0$ b)

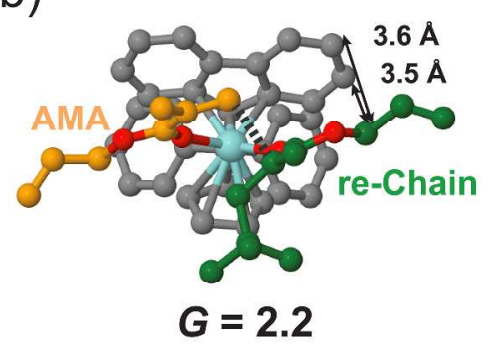

d)

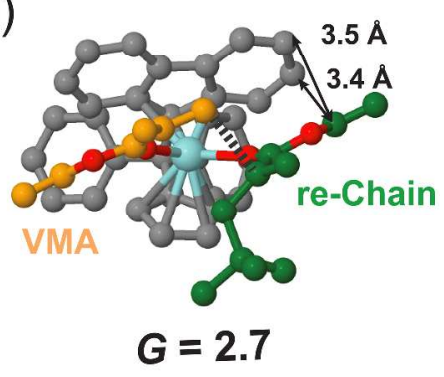

Figure 9. Transition state geometries of the competitive addition at the si and re face of the growing chain for AMA (a and b) and VMA (c and d), respectively, with $(S)-\mathrm{Ph}_{2} \mathrm{C}(\mathrm{Cp}) \mathrm{Flu}-\mathrm{Zr}$ system (5). The free energies ( $\mathrm{kcal} / \mathrm{mol}, \mathrm{DCM})$ are relative to the TS involving the si face of the growing chain (a and $\mathbf{c})$. The dashed line indicates the emerging $\mathrm{C}-\mathrm{C}$ bonds.

Post-Functionalization and Photocrosslinking to Functional Materials. Post-functionalization of syndiotactic polymers bearing the pendant vinyl $\left(-\mathrm{CH}=\mathrm{CH}_{2}\right)$ functional group on every repeating unit was performed through two approaches: the thiol-ene "click" reaction and photocuring. The former 
approach has been widely used and proven to be highly effective for functionalization of ene-bearing polymers. ${ }^{29}$ We first examined functionalization of $s t$-PVMA $\left(M_{\mathrm{n}}=40.9 \mathrm{~kg} / \mathrm{mol}, \oslash=1.19\right)$ and $s t$-PDAA $\left(M_{\mathrm{n}}=373 \mathrm{~kg} / \mathrm{mol}, Ð=1.43\right)$ with two model thiols, 4-tert-butylbenzylmercaptan (RSH1) and 1adamantanethiol (RSH2), using the click reaction with 2,2-dimethoxy-2-phenylacetophenone (DMPA) as the photoradical initiator under photochemical conditions (RT, UV lamp centered at $\lambda=350 \mathrm{~nm}$ ) in chloroform (Scheme 3). The pendant vinyl groups were completely converted into new $-\mathrm{CH}_{2} \mathrm{CH}_{2}-\mathrm{SR}$ groups, as confirmed by ${ }^{1} \mathrm{H}$ NMR spectra (Figure 10 \& Figure S5), which also showed that the tacticity of the resulting thiolated polymers was the same as the parent polymers in all the cases. GPC analysis of the thiolated polymers, which are all soluble in chloroform, showed an increase in the $M_{\mathrm{n}}$ and $\oslash$ values (Figure S6), indicative of some degree of light crosslinking due to the non-selective radical initiation in the presence of the high concentration of reactive $\mathrm{C}=\mathrm{C}$ pendant groups. The thermal properties of the functionalized polymers were also significantly affected by the inclusion of the -SR groups. For instance, the first-step onset decomposition temperature $\left(T_{\mathrm{d}}\right)$ of $s t$-PVMA $\left(234{ }^{\circ} \mathrm{C}\right)$ measured by thermal gravimetric analysis (TGA) was enhanced by $62{ }^{\circ} \mathrm{C}$ to $T_{\mathrm{d}}=296{ }^{\circ} \mathrm{C}$ of both $s t$-PVMA-SR 1 and $s t$-PVMASR2 (Figure S7), attributed to the transformation of the $-\mathrm{OCH}=\mathrm{CH}_{2}$ group into the $-\mathrm{OCH}_{2} \mathrm{CH}_{2} \mathrm{SR}$ moiety, which was accompanied by a change in the $T_{\mathrm{g}}$ from $102{ }^{\circ} \mathrm{C}$ of $s t$-PVMA to $39{ }^{\circ} \mathrm{C}$ and $118{ }^{\circ} \mathrm{C}$ of $s t$ PVMA-SR1 and st-PVMA-SR2, respectively (Figure S8, top). In sharp contrast, st-PDAA exhibited a lower $T_{\mathrm{g}}$ (Figure S8, bottom), but high thermal stability than its thiolated polymers $s t$-PDAA-SR1 and $s t$ PDAA-SR2 (Figure S9). 


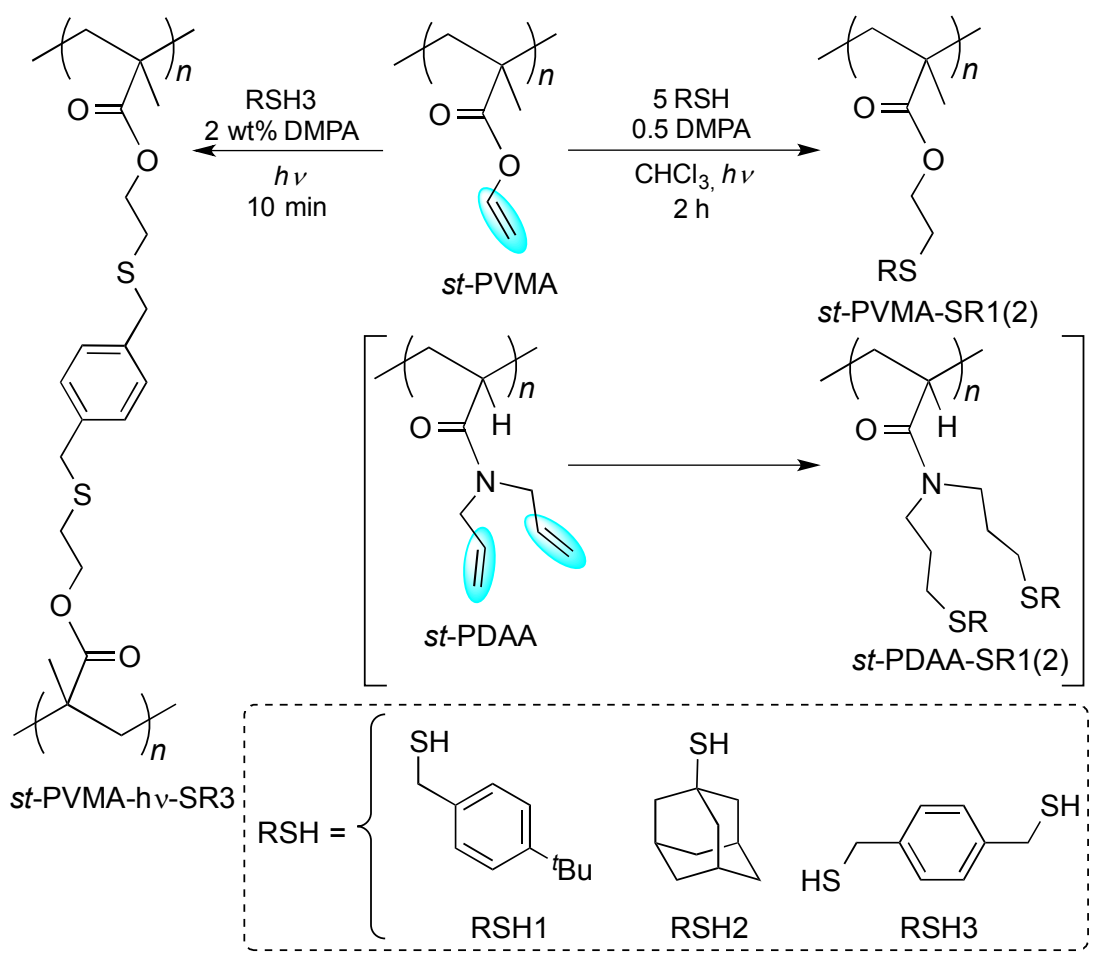

Scheme 3. Post-functionalization of $s t$-PVMA and st-PDAA via the thiol-ene "click" chemistry.

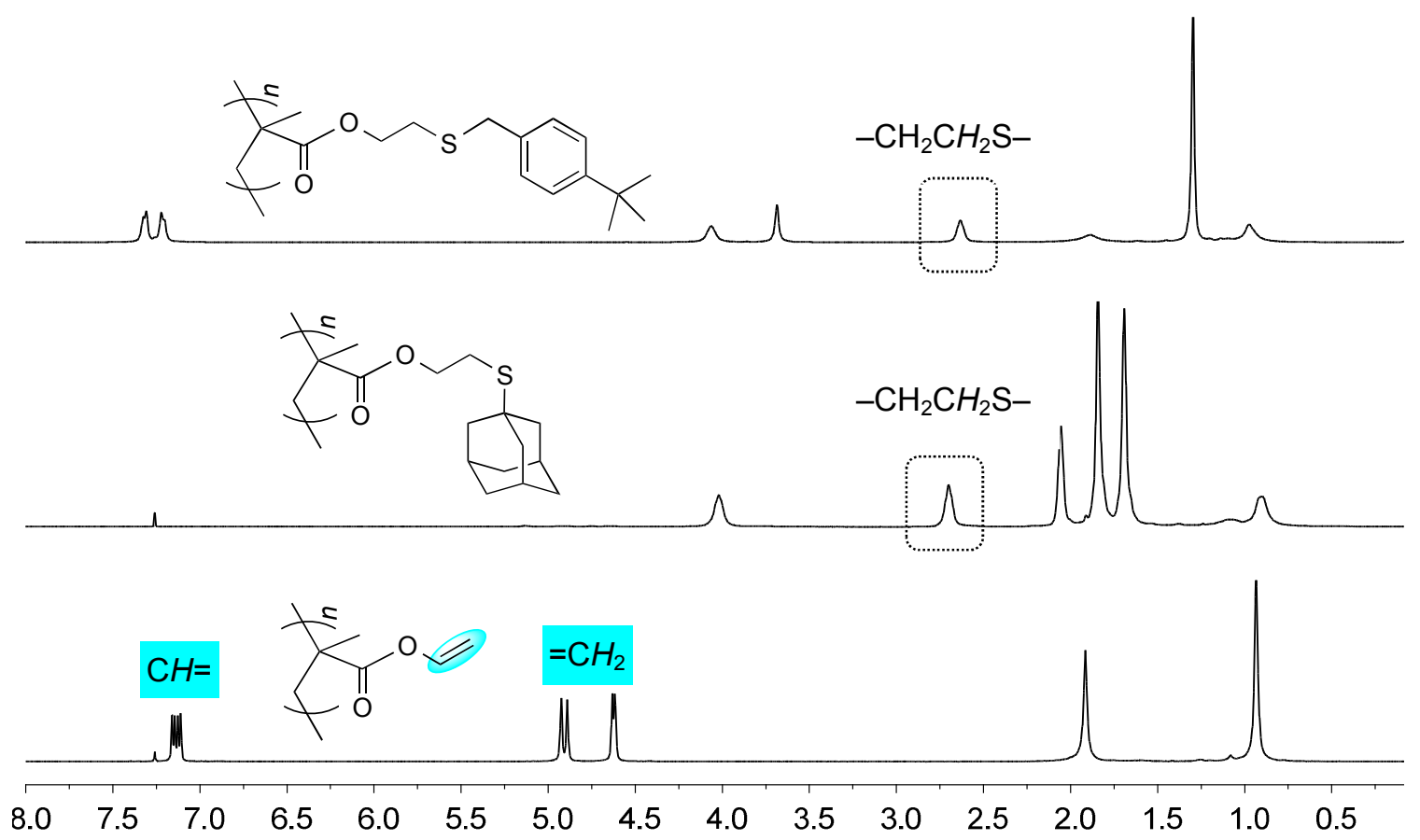

Figure 10. Overlay of ${ }^{1} \mathrm{H}$ NMR $\left(\mathrm{CDCl}_{3}, 25^{\circ} \mathrm{C}\right)$ spectra of st-PVMA (bottom), st-PVMA-SR1 (top), and $s t$-PVMA-SR2 (middle). 
Owing to the presence of the pendant vinyl groups, st-PVMA can also be readily photocured into flexible thin films for examining their thermo-mechanical properties. Thus, a solvent casted st-PVMA film was subjected to controlled crosslinking conditions under UV (350 nm) photoradical initiation with DMPA inside a Luzchem photoreactor for $10 \mathrm{~min}$, producing a flexible, translucent, colorless thin film (st-PVMA-hv, Figure 11). A crosslinker, 1,4-benzenedimethanethiol (RSH3), was also added in varied amounts $(2.5,5$, and $10 \mathrm{~mol} \%)$ to prepare films with increased crosslinking and brittleness as the amount of RSH3 increases. Dynamic mechanical analysis (DMA) showed an increase in $T_{\mathrm{g}}$ from the parent $s t$ PVMA film $\left(105^{\circ} \mathrm{C}\right)$ to the photocured $s t$-PVMA- $h v$ film $\left(111^{\circ} \mathrm{C}\right)$ after 10 min of UV irradiation, which was accompanied by an increase in both storage modulus $\left(E^{\prime}\right)$ and loss modulus $\left(E^{\prime \prime}\right)$ in both glassy (values reported at $25^{\circ} \mathrm{C}$ ) and rubbery (values reported at $150^{\circ} \mathrm{C}$ ) states, Figure 12 and Table 2 (entry 2 vs. 1). A further increase in $T_{\mathrm{g}}$ (measured by the peak maxima of the $\tan \delta\left(E^{\prime \prime} / E^{\prime}\right)$ curve in the DMA analysis) to 112,121 , and $128{ }^{\circ} \mathrm{C}$ was observed when the amount of the added crosslinker RSH3 was increased from 2.5 to 5.0 to $10 \mathrm{~mol} \%$, respectively (Table 2 ). This observed increasing $T_{\mathrm{g}}$ trend is a result of an increase in the degree of crosslinking, as characterized by the gradual increase in both $E^{\prime}$ and $E^{\prime \prime}$ values in the rubbery state (values reported at $150{ }^{\circ} \mathrm{C}$, from entries 3 to 5 , Table 2). On the other hand, TGA traces of all the thin films derived from st-PVMA were rather similar, displaying similar decomposition profiles (Figure S10). Likewise, a thin film of st-PDAA was also solvent casted and subsequently photocured in the presence of $2 \mathrm{wt} \%$ of DMPA. The resulting material, st-PDAA- $h v$, exhibited a $T_{\mathrm{g}}$ of $56.1^{\circ} \mathrm{C}$ as measured by DMA (Figure $\mathrm{S} 11$ ).

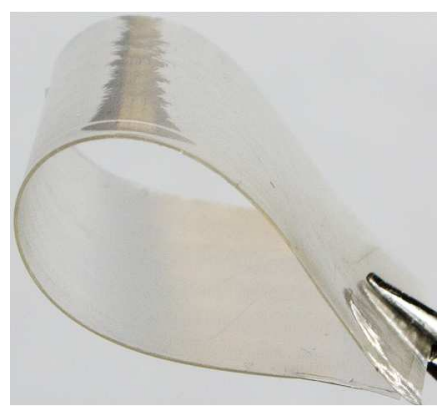

Figure 11. Photograph of solvent casted and photocured $s t$-PVMA- $h v$ film (0.06 mm thick). 

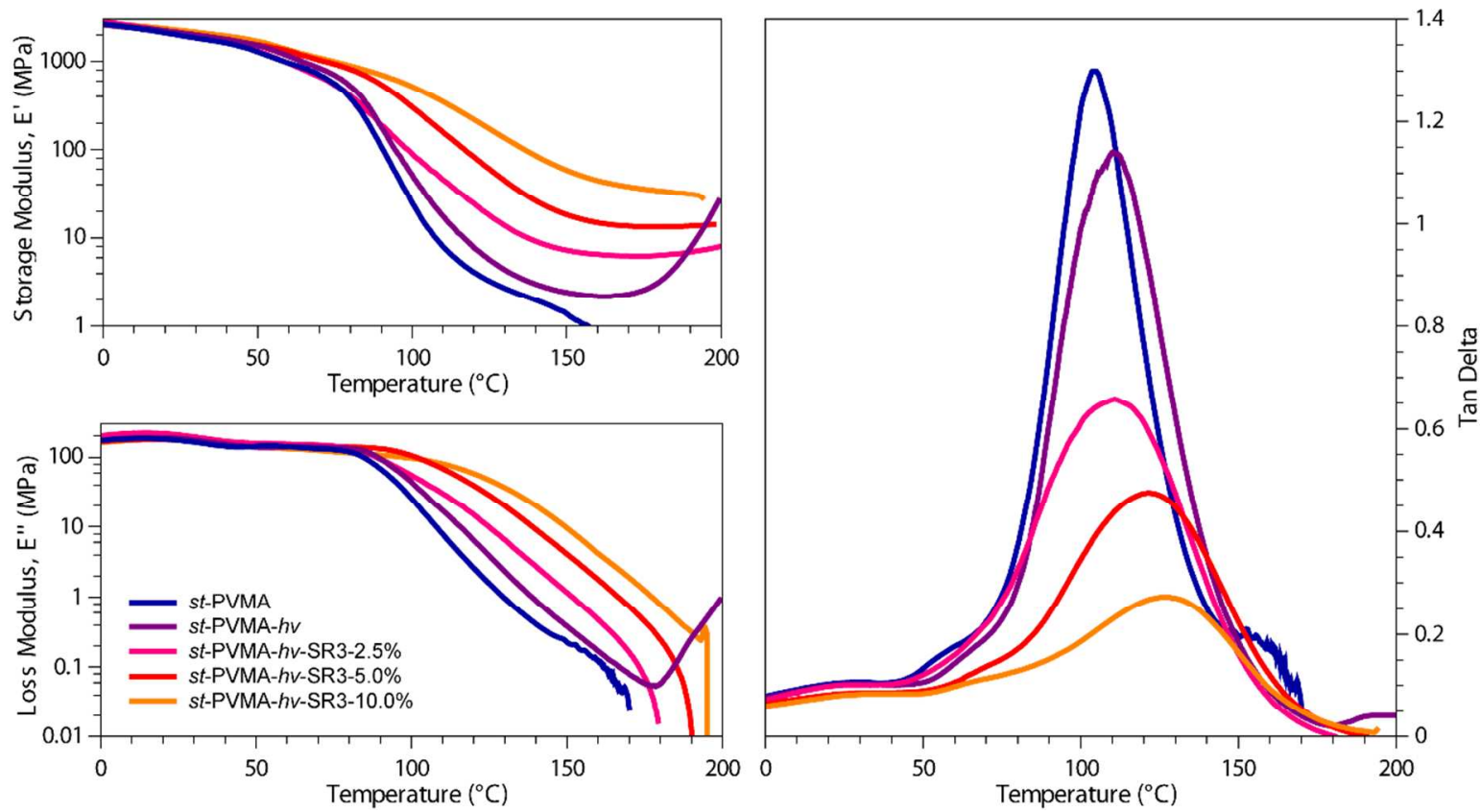

Figure 12. Storage modulus ( $E^{\prime}$, top left), loss modulus ( $E^{\prime \prime}$, bottom left), and $\tan \delta$ ( $E^{\prime \prime} / E^{\prime}$, right) of $s t$ PVMA (blue), photocured $s t$-PVMA- $h v$ (purple), st-PVMA- $h v$-SR3-2.5\% (pink), st-PVMA- $h v-S R 3-5 \%$ (red), and $s t$-PVMA- $h v$-SR3-10\% (orange) determined by DMA analysis $\left(3{ }^{\circ} \mathrm{C} \min ^{-1}\right.$ temperature ramp rate).

Table 2. Selected thermo-mechanical properties of parent and photo-cured polymers characterized by DMA

\begin{tabular}{clccccc}
\hline $\begin{array}{c}\text { entry } \\
\text { no. }\end{array}$ & \multicolumn{1}{c}{ Polymer } & $\begin{array}{c}T_{\mathrm{g}} \\
\left({ }^{\circ} \mathrm{C}\right)\end{array}$ & $\begin{array}{c}E^{\prime}, 25^{\circ} \mathrm{C} \\
(\mathrm{GPa})\end{array}$ & $\begin{array}{c}E^{\prime \prime}, 25^{\circ} \mathrm{C} \\
(\mathrm{MPa})\end{array}$ & $\begin{array}{c}E^{\prime}, 150^{\circ} \mathrm{C} \\
(\mathrm{MPa})\end{array}$ & $\begin{array}{c}E^{\prime \prime}, 150{ }^{\circ} \mathrm{C} \\
(\mathrm{MPa})\end{array}$ \\
\hline 1 & $s t$-PVMA & 105 & 1.64 & 171 & 1.16 & 0.22 \\
2 & $s t$-PVMA- $h v$ & 111 & 1.75 & 190 & 1.96 & 0.34 \\
\hline 3 & st-PVMA- $h v-\mathrm{SR} 3-2.5 \%$ & 112 & 1.73 & 178 & 6.00 & 0.95 \\
4 & st-PVMA- $h v$-SR3-5\% & 121 & 2.06 & 175 & 18.3 & 4.11 \\
5 & st-PVMA- $h v$-SR3-10\% & 128 & 1.32 & 107 & 34.5 & 5.67 \\
6 & st-PDAA- $h v$ & 56.1 & 1.04 & 90.7 & 49.8 & 5.47 \\
\hline
\end{tabular}

\section{Stereocomplexation and Photocuring to Robust Crosslinked Stereocomplexes.}

Stereocomplexes of diastereomeric polymer chains were formed effectively by mixing $10 \mathrm{mg} / \mathrm{mL}$ acetone solutions of it-PMMA with st-PVMA (designated sc-PMMA-PVMA, Figure 1) or it-PMMA with stPAMA (designated $s c$-PMMA-PAMA) at $40{ }^{\circ} \mathrm{C}$ in $1: 1$ and $1: 2 \mathrm{it}-/$ st-polymer ratios, which were left to 
slowly crystallize at room temperature to obtain colorless, transparent thin films. The formation of such stereocomplexes is readily evident by observing a characteristic $T_{\mathrm{m}}$ peak from the DSC curves (Figure 13 and Figure S12) and a characteristic diffraction peak at $2 \theta=4.56^{\circ}(d=1.94 \mathrm{~nm})$ from the pXRD patterns (Figure 14a). ${ }^{18}$ Interestingly, the $T_{\mathrm{m}}$ of the stereocomplexes was not significantly affected by the molar ratio of the diasteromeric polymer pair tested (1:1 vs. 1:2), but it is sensitive to the molecular weight of the $i t$-PMMA component (Table 3). For instance, sc-PMMA-PVMA showed a $T_{\mathrm{m}}$ of $165^{\circ} \mathrm{C}$ and $164{ }^{\circ} \mathrm{C}$ (in 1:1 and 1:2 ratios, respectively) with it-PMMA of $M_{\mathrm{n}}=26.4 \mathrm{~kg} / \mathrm{mol}(\bigoplus=1.06,[\mathrm{~mm}]=92.2)$, while the same stereocomplex displayed a much higher $T_{\mathrm{m}}$ of $188{ }^{\circ} \mathrm{C}$ and $186{ }^{\circ} \mathrm{C}$ (in $1: 1$ and $1: 2$ ratios, respectively) with it-PMMA of much higher molecular weight $\left(M_{\mathrm{n}}=136 \mathrm{~kg} / \mathrm{mol}, \oslash=1.19,[\mathrm{~mm}]=96.4\right)$. As expected, it-PAMA did not form a stereocomplex with either st-PAMA or st-PVMA in different ratios (1:1 and 1:2) and solvents (acetone and toluene) but, surprisingly, it-PAMA produced a weak stereocomplex with st-PMMA in both 1:1 and 1:2 ratios from their blends in acetone solutions, as revealed by broad $T_{\mathrm{m}}$ transitions of $119^{\circ} \mathrm{C}$ (Figure 13 a) and $120^{\circ} \mathrm{C}$, respectively. To further examine the effects of the ester group in the isotactic polymer chain on the formation of stereocomplexes, we also attempted the stereocomplexation between isotactic poly $\left(n\right.$-butyl methacrylate) $\left([\mathrm{mm}]=96.9 \%, M_{\mathrm{n}} \sim 28\right.$ $\mathrm{kg} / \mathrm{mol}$ ) and $s t$-PVMA or $s t$-PAMA in acetone (complexing solvent) in 1:1 and 1:2 it/st molar ratios. However, the resulting materials showed only two $T_{\mathrm{g}}$ 's corresponding to the constituent polymers, indicating that the stereocomplexation was hindered by the size of the $n$-butyl ester group of the isotactic polymer chain.

Control experiments by mixing it-PMMA with st-PVMA or st-PAMA in $\mathrm{CH}_{2} \mathrm{Cl}_{2}$ in a $1: 1$ it/st ratio led to amorphous polymer blends, which exhibited only the glass transitions corresponding to the constituent polymers of the blends, plus typical crosslinking exotherms of the vinyl-containing polymers appeared at temperatures higher than $150{ }^{\circ} \mathrm{C}$. These results indicate that, just like $s c$-PMMA-PMMA, $\mathrm{CH}_{2} \mathrm{Cl}_{2}$ is also a non-complexing solvent for stereocomplexes sc-PMMA-PVMA and sc-PMMA-PAMA, the formation of which requires the use of complexating solvents such as acetone or toluene. 


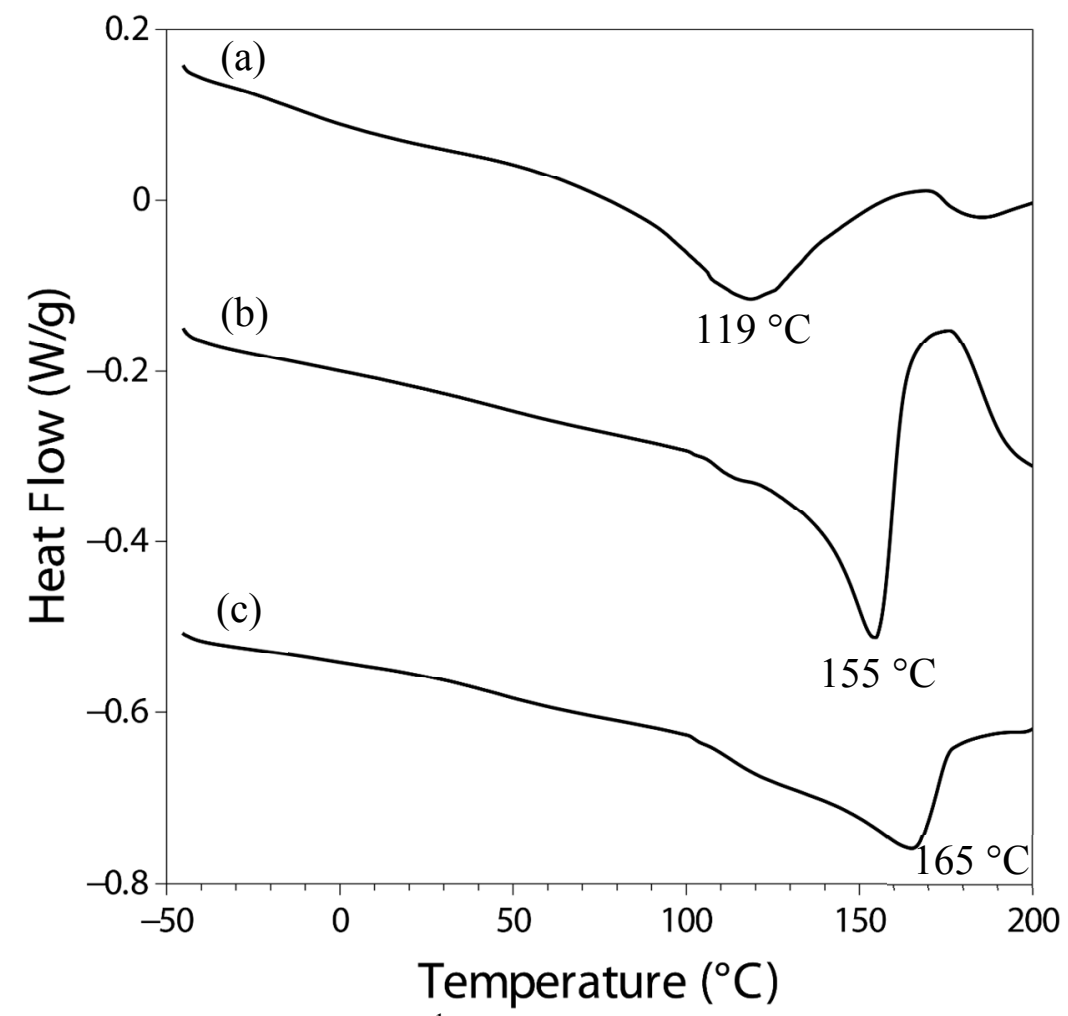

Figure 13. Representative DSC $\left(10^{\circ} \mathrm{C} \mathrm{min}^{-1}\right)$ curves: (a) sc-PAMA-PMMA (Table 3, entry 1); (b) $s c$ PMMA-PAMA (Table 3, entry 3); and (c) sc-PMMA-PVMA (Table 3, entry 11) obtained by crystallization from acetone solutions. 


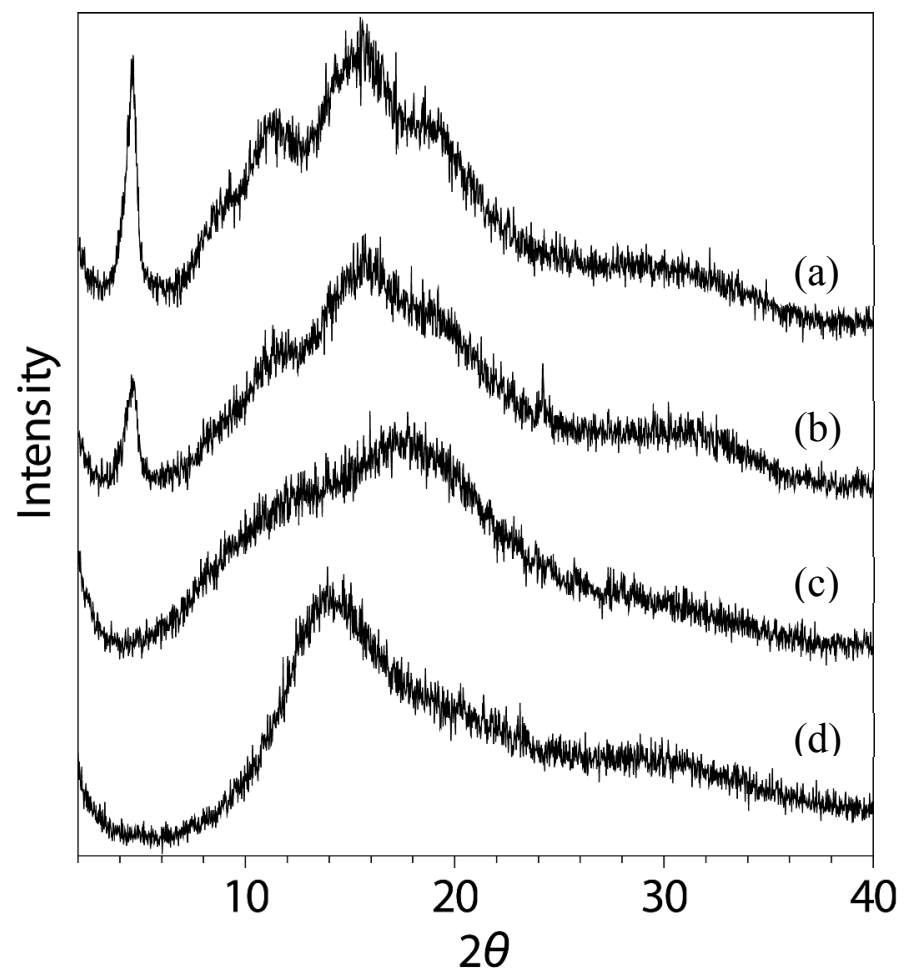

Figure 14. pXRD patterns of $s c$-PMMA-PVMA (a) and photocrosslinked $s c$-PMMA-PVMA- $h v$ (b). Constituent diastereomeric polymers st-PVMA (c) and it-PMMA (d) included as a comparison.

Table 3. Stereocomplexation and photocrosslinking results ${ }^{a}$

\begin{tabular}{|c|c|c|c|c|c|c|c|}
\hline $\begin{array}{c}\text { entry } \\
\text { no. }\end{array}$ & $\begin{array}{l}\text { syndiotactic } \\
\text { polymer }\end{array}$ & isotactic polymer & $\begin{array}{c}\text { molar } \\
\text { ratio } \\
(\text { st } / i t) \\
\end{array}$ & $\begin{array}{l}T_{\mathrm{m}}{ }^{b} \\
\left({ }^{\circ} \mathrm{C}\right)\end{array}$ & $\begin{array}{l}\text { crosslinked } \\
\text { vinyl } \\
\text { polym. }^{c}(\%) \\
\end{array}$ & $\begin{array}{c}\text { trapped } \\
\text { PMMA }^{c} \\
(\%) \\
\end{array}$ & $\begin{array}{l}\text { PMMA } \\
\text { trapping } \\
\text { eff. }^{c}(\%) \\
\end{array}$ \\
\hline 1 & st-PMMA & $i t$-PAMA & $1: 1$ & 119 & 91.4 & 15.6 & 29 \\
\hline 2 & st-PAMA & - & - & - & 97.2 & - & - \\
\hline 3 & & low MW it-PMMA & $1: 1$ & 155 & 77.7 & 12.5 & 23.0 \\
\hline 4 & & low MW it-PMMA & $2: 1$ & 157 & 85.8 & 20.0 & 29.9 \\
\hline 5 & & high MW it-PMMA & $1: 1$ & 165 & 85.5 & 51.8 & 73.4 \\
\hline 6 & & high MW it-PMMA & $2: 1$ & 168 & 84.7 & 50.5 & 67.2 \\
\hline 7 & & $(i t-\mathrm{PMMA})_{0.83}-b-(i t-\mathrm{PAMA})_{0.17}$ & $1: 1$ & 168 & 63.7 & 49.1 & 86.7 \\
\hline 8 & & $(i t \text {-PMMA })_{0.67}-b-(a t-\mathrm{PVMA})_{0.33}$ & $1: 1$ & 170 & 79.0 & 63.0 & 89.6 \\
\hline 9 & & $(i t \text {-PMMA })_{0.88}$-ran-(it-PAMA $)_{0.12}$ & $1: 1$ & - & 94.4 & 86.9 & 95.5 \\
\hline 10 & $s t$-PVMA & - & - & - & 58.3 & - & $-{ }^{-}$ \\
\hline 11 & & low MW it-PMMA & $1: 1$ & 165 & 56.5 & 56.2 & 99.6 \\
\hline 12 & & low MW it-PMMA & $2: 1$ & 164 & 56.2 & 13.5 & 31.4 \\
\hline 13 & & high MW it-PMMA & $1: 1$ & 188 & 62.7 & 50.5 & 88.6 \\
\hline 14 & & high MW it-PMMA & $2: 1$ & 186 & 54.1 & 39.0 & 78.7 \\
\hline 15 & & $(i t \text {-PMMA })_{0.83}-b-(i t-\mathrm{PAMA})_{0.17}$ & $1: 1$ & 181 & 66.4 & 58.5 & 93.9 \\
\hline 16 & & $(i t \text {-PMMA })_{0.67}-b-(a t-\mathrm{PVMA})_{0.33}$ & $1: 1$ & 182 & 71.1 & 59.8 & 92.6 \\
\hline
\end{tabular}

${ }^{a}$ Polymer data: st-PAMA, $M_{\mathrm{n}}=39.9 \mathrm{kDa}, \ominus=1.45,[\mathrm{rr}]=91.8 ;$ it-PAMA, $M_{\mathrm{n}}=32.4 \mathrm{kDa}, \emptyset=1.10,[\mathrm{~mm}]=96.5$; $s t$-PVMA, $M_{\mathrm{n}}=52.1 \mathrm{kDa}, \oslash=1.31,[r r]=91.7$; st-PMMA, $M_{\mathrm{n}}=36.3 \mathrm{kDa}, Ð=1.29,[r r]=93.7$; low MW it- 
PMMA, $M_{\mathrm{n}}=26.4 \mathrm{kDa}, \oslash=1.06,[\mathrm{~mm}]=92.2$; high MW it-PMMA, $M_{\mathrm{n}}=136.1 \mathrm{kDa}, Ð=1.19,[\mathrm{~mm}]=96.4 ;$; $(i t-$ PMMA $)_{0.83}-b-(i t-P A M A)_{0.17}, M_{\mathrm{n}}=89.6 \mathrm{kDa}, \oslash=1.37,[\mathrm{~mm}]=93.1 \%$; $(i t \text {-PMMA })_{0.67}-b-(a t \text {-PVMA })_{0.33}, M_{\mathrm{n}}=76.8$ $\mathrm{kDa}, \oslash=1.49,[\mathrm{~mm}]=79.8 \%,(i t-\mathrm{PMMA})_{0.88}$ ran- $(\text { at }-\mathrm{PAMA})_{0.12}, M_{\mathrm{n}}=156 \mathrm{kDa}, \oslash=1.83,[\mathrm{~mm}]=95.9 \% .{ }^{b} T_{\mathrm{m}}$ measured by DSC. ${ }^{c}$ See the SI for the quantification method.

Under UV (350 nm) irradiation in the presence of photoradical initiator DMPA, the stereocomplex $s c$-PMMA-PVMA was successfully photocured into crosslinked, insoluble stereocomplex sc-PMMAPVMA- $h v(c . f .$, Figure 1). The photocured stereocomplex exhibited a broad melting transition centered at $\sim 150{ }^{\circ} \mathrm{C}$ (Figure S13), and a characteristic diffraction peak at $2 \theta=4.56{ }^{\circ} \mathrm{C}(d=1.94 \mathrm{~nm})$ (Figure $\left.14 \mathrm{~b}\right)$, thus confirming the stereocomplex structure is retained after crosslinking. Thin films of $s c$-PMMAPVMA and photocrosslinked $s c$-PMMA-PVMA- $h v$ were prepared and subsequently analyzed by DMA (Figure 15). While it-PMMA and st-PVMA showed a single sharp glass transition $T_{\mathrm{g}}$ at $45.2{ }^{\circ} \mathrm{C}$ and 105 ${ }^{\circ} \mathrm{C}$, respectively, measured by the maxima of the $\tan \delta$ curve, the stereocomplex sample sc-PMMAPVMA showed two weak transitions at higher temperatures of $62.2^{\circ} \mathrm{C}$ and $135^{\circ} \mathrm{C}$. The photocrosslinked samples $s c$-PMMA-PVMA- $h v$ exhibited a similar behavior with a shift of the transitions to even higher temperatures of $67.2{ }^{\circ} \mathrm{C}$ and $158^{\circ} \mathrm{C}$, attributable to the crosslinking of the polymer networks. Noteworthy also is that the stereocomplex exhibited considerably higher storage modulus than its constituent itPMMA and st-PVMA at high temperatures and that the crosslinked stereocomplex had the highest modulus. For instance, at $95^{\circ} \mathrm{C}, E^{\prime}$ was measured to be $0.713,43.8,175$, and $392 \mathrm{MPa}$ for $i t$-PMMA, stPVMA, sc-PMMA-PVMA, and sc-PMMA-PVMA- $h v$, respectively. Overall, these thermo-mechanical and X-ray diffraction analysis results demonstrate that stereocomplex formation significantly increases storage and loss moduli over the constituent it- and st-polymers at temperatures $>100{ }^{\circ} \mathrm{C}$ and that the photocured stereocomplex retains the stereocomplex structure but with considerably enhanced thermal and mechanical properties of the material. 

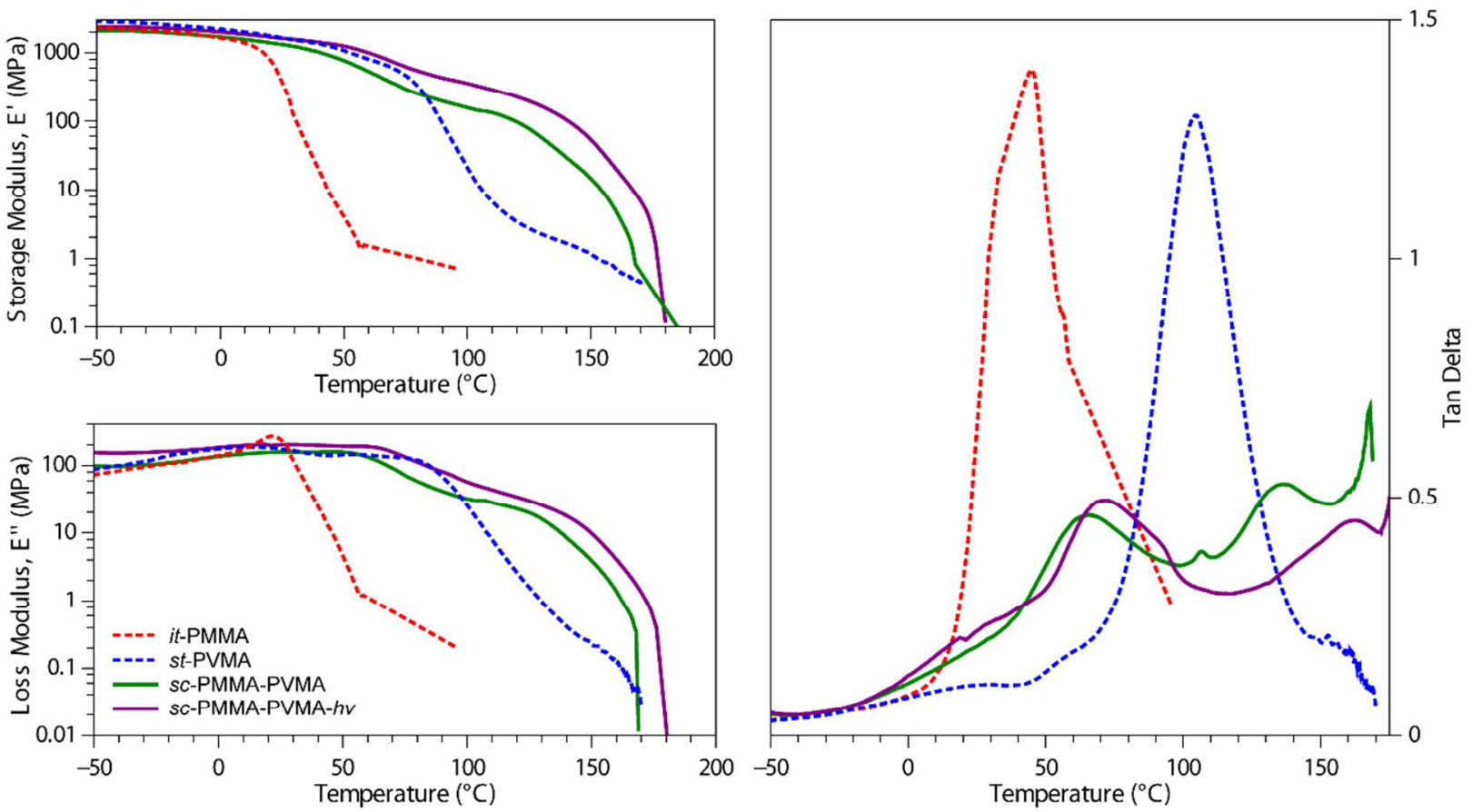

Figure 15. Storage modulus ( $E^{\prime}$, top left), loss modulus ( $E^{\prime \prime}$, bottom left), and $\tan \delta\left(E^{\prime \prime} / E^{\prime}\right.$, right) of itPMMA (red), st-PVMA (blue), sc-PMMA-PVMA (green), and sc-PMMA-PVMA- $h v$ (purple) determined by DMA analysis $\left(3^{\circ} \mathrm{C} \mathrm{min}^{-1}\right.$ temperature ramp rate).

Besides the above demonstrated enhanced thermal and mechanical properties of the crosslinked stereocomplex, we anticipate another novel feature of the crosslinked stereocomplex: it should be solvent resistant and thus cannot be decomplexed in a non-complexing (or decomplexing) solvent such as chloroform, in contrast to the conventional it-PMMA/st-PMMA stereocomplex. To this end, we examined if the it-PMMA helical chains can be trapped inside the stereocomplex crosslinked via the outer helical layer of the vinyl-containing st-polymer. At the outset, a control experiment that consisted of a sample of $s c$-PMMA (a mixture of $i t$-PMMA and $s t$-PMMA in 1:1 ratio) containing $2 \mathrm{wt} \%$ of DMPA and subjected to UV irradiation $(\lambda=350 \mathrm{~nm})$ for $2 \mathrm{~h}$ showed that the resulting stereocomplex was still completely soluble in chloroform and no PMMA was trapped due to no crosslinked chains. Using thermal crosslinking to trap the it-PMMA chains by annealing stereocomplex samples of sc-PMMA-PVMA and 
$s c$-PMMA-PAMA over $200{ }^{\circ} \mathrm{C}$, at which temperature thermal crosslinking occurs, was unsuccessful; while the st-polymer was successfully crosslinked at this temperature, the it-PMMA chains were released from the melt. Next, $s c$-PMMA-PVMA and $s c$-PMMA-PAMA were photocrosslinked with $2 \mathrm{wt} \%$ of DMPA under UV irradiation $(\lambda=350 \mathrm{~nm})$ for $2 \mathrm{~h}$ at room temperature. The crosslinked material was extracted with chloroform (a decomplexing solvent) for $24 \mathrm{~h}$ at $40{ }^{\circ} \mathrm{C}$ to promote the possible release of the complexed, but untrapped, it-PMMA. The amount of the crosslinked st-polymer as well as the trapped it-PMMA was quantified by ${ }^{1} \mathrm{H}$ NMR analysis (see the SI). The it-PMMA trapping efficiency was calculated as the percentage of the experimental it-PMMA content ( $\mathrm{wt} \%)$ found $v s$ the theoretical itPMMA content in the crosslinked stereocomplex if all the initial it-PMMA was effectively trapped. Table 3 summarized our study of $i t$-PMMA trapping efficiency as a function of (a) it-PMMA molecular weight; (b) molar ratio of it-PMMA to st-PVMA (or st-PAMA); and (c) use of block and random copolymers incorporating the photo-crosslinkable units.

The results summarized in Table 3 showed that a control sample of st-PAMA afforded a much higher degree of crosslinking (97.2\%) compared to st-PVMA (58.3\%) when photocured under the same conditions. Similarly, stereocomplexes containing both it-PAMA and st-PAMA samples were more effectively photocrosslinked (from $63.7 \%$ to $91.4 \%$ degree of crosslinking) than those containing stPVMA (which achieved only $54.1 \%$ to $71.1 \%$ ). Note that the self-crosslinking ability of st-PVMA in a sample crystallized from a $\mathrm{CH}_{2} \mathrm{Cl}_{2}$ solution (Table $\mathrm{S} 1$ ) was higher $(82.4 \%)$, indicating that crystallization conditions impact the self-crosslinking ability of st-PVMA in the solid state. Under both conditions (acetone and $\mathrm{CH}_{2} \mathrm{Cl}_{2}$ ) tested, st-PAMA showed considerably better self-crosslinking ability ( $\left.>95 \%\right)$ than $s t$-PVMA, indicating that a longer, more flexible allyl ester group can be more efficiently crosslinked than the shorter and more rigid vinyl group in the VMA repeat unit. Stereocomplexes of $s c$-PMMA-PAMA with high MW it-PMMA $\left(M_{\mathrm{n}}=136.1 \mathrm{~kg} / \mathrm{mol}, Ð=1.19\right)$ achieved a higher PMMA trapping effiency (up to $73.4 \%$, entry 5 ) than those stereocomplexes (up to 29.9 , entry 4$)$ with low MW it-PMMA $\left(M_{\mathrm{n}}=26.4\right.$ $\mathrm{kg} / \mathrm{mol}, \emptyset=1.06$ ). No correlation was observed between the PMMA trapping efficiency and the molar 
ratio of the diastereomeric polymer pair. To possibly further enhance the PMMA trapping efficiency, we employed a new strategy of using block copolymers of it-PMMA with PAMA and PVMA to form stereocomplexes with $s t$-PAMA and st-PVMA. Indeed, the PMMA trapping efficiency was enhanced to 86.7 and $89.6 \%$ (entries 7 and 8), indicating that a portion of the crosslinkable block is also photocured. The highest PMMA trapping efficiency of 95.5\% (entry 9) was obtained from a blend of st-PAMA with a random copolymer, $\left(\text { it-PMMA) }{ }_{0.88} \text {-ran-(it-PAMA }\right)_{0.12}$, but the stereocomplexation was hindered by the random placement of AMA units in the it-PMMA chain. In comparison, the PMMA trapping efficiency was generally higher (up to quantitative) for the stereocomplexes formed with st-PVMA (entries 11-16) than those with st-PAMA (entries 3-9). Again, higher PMMA trapping efficiencies were observed when block-copolymers containing crosslinkable AMA or VMA units were employed as the isotactic component to form the stereocomplex (>92.6\%, entries 15 and 16$)$.

Additional control studies used the non-stereocomplexed control samples prepared by mixing itPMMA with st-PVMA or st-PAMA in a non-complexing solvent $\left(\mathrm{CH}_{2} \mathrm{Cl}_{2}\right)$, which were photocured under identical conditions to those reported for Table 3. The samples were further analyzed to quantify the capacity of the crosslinked st-vinyl polymers to trap it-PMMA and the results were summarized in Table S1. The results showed that the it-PMMA trapping efficiency was almost negligible (0.6 to $2.6 \%$ ), indicating that the photocrosslinked polymer blends are not capable of trapping the it-PMMA chains. These control experiments highlight the importance of the polymer supramolecular structure to efficiently trap the it-PMMA chains, achievable only when the stereocomplexes are formed. For instance, while the sc-PMMA-PVMA formed in acetone had a PMMA trapping efficiency of $99.6 \%$ (entry 11, Table 3), the same mixture made in $\mathrm{CH}_{2} \mathrm{Cl}_{2}$ only showed a PMMA trapping efficiency of $2.6 \%$ (entry 4 , Table $\mathrm{S} 1$ ).

We also investigated the possible complexation of st-PVMA and st-PAMA with fullerene $\mathrm{C}_{60}$ to form an inclusion complex, $i c-\mathrm{PVMA}-\mathrm{C}_{60}$ or $i c-\mathrm{PAMA}-\mathrm{C}_{60}$. The material formed between st-PVMA and $\mathrm{C}_{60}$ exhibited a broad melting transition peak at temperature $>150^{\circ} \mathrm{C}$, which was overlapped with much intense exothermic peaks (due to thermally induced crosslinking), thus offering no clear evidence for the 
inclusion complex formation. However, we obtained conclusive evidence that st-PAMA readily forms inclusion complexes ic-PAMA- $\mathrm{C}_{60}$ (Figure 16) with $\mathrm{C}_{60}$ in different ratio combinations (Table 4). The formation of such inclusion complex was evidenced by the appearance of a sharp melting transition from 200 to $211^{\circ} \mathrm{C}$ (Figure 17), observed from the DSC analysis of the resulting product after crystallization. The DSC thermograms of commercial fullerene $\mathrm{C}_{60}$, st-PAMA, a non-inclusion mixture of st-PAMA/ $\mathrm{C}_{60}$ (obtained from the annealing of the blend at $80^{\circ} \mathrm{C}$ for $20 \mathrm{~h}$ ), and $i c-P A M A-\mathrm{C}_{60}$ are shown in Figure 18 for comparison. The first-order transition in the DSC thermogram of $\mathrm{C}_{60}$ corresponds to the well-known phase transition between a simple cubic (sc) lattice (below the $T_{\mathrm{tr}}=-14.8^{\circ} \mathrm{C}$ ) and a face-centered cubic lattice (fcc).$^{30}$ The st-PAMA shows a $T_{\mathrm{g}}$ of $49.9{ }^{\circ} \mathrm{C}$, plus broad thermal crosslinking exothermic peak at temperature $>150{ }^{\circ} \mathrm{C}$, whereas the non-inclusion complex mixture of st-PAMA/ $\mathrm{C}_{60}$ shows both mentioned features of the individual components. In sharp contrast, the $i c-P A M A-C_{60}$ obtained by crystallization from toluene exhibits a novel feature: a markedly sharp melting transition at $T_{\mathrm{m}}=205{ }^{\circ} \mathrm{C}$, indicative of the inclusion complex formation.

Three approaches were explored to produce crosslinked ic-PAMA-C 60 . First, photochemically induced radical crosslinking with DMPA as the initiator under UV irradiation $(\lambda=350 \mathrm{~nm})$ in solution or solid state did not produce the crosslinked product, as the crystallized material was again completely soluble in toluene. Second, thermally induced radical crosslinking with BPO (benzoyl peroxide) as the initiator also failed to afford the target crosslinked $i c$-PAMA- $\mathrm{C}_{60}$. Third, recognizing $\mathrm{C}_{60}$ as an excellent radical trap, ${ }^{31}$ we turned out attention to non-radical crosslinking methods. To this end, successful crosslinking of $i c-$ PAMA- $\mathrm{C}_{60}$ was achieved using $2 \mathrm{~mol} \%$ of the Grubbs catalyst $\left(2^{\text {nd }} \mathrm{Gen} .\right)^{32}$ in toluene at room temperature for $2 \mathrm{~h}$ (Figure 16; entries 3-5, Table 4). However, the DSC thermogram of the material obtained from the solution-phase metathesis crosslinking of ic-PAMA- $\mathrm{C}_{60}$ exhibited no melting transition peak but a $T_{\mathrm{g}}$ of $106{ }^{\circ} \mathrm{C}$, which is about $50{ }^{\circ} \mathrm{C}$ higher than the parent st-PAMA. This result indicates most, if not all, the helical inclusion complex structure was disrupted by this solution crosslinking reaction to form a mostly amorphous crosslinked structure (Figure 16). 
Table 4. Results of complexation between st-PAMA and $\mathrm{C}_{60}$ and subsequent crosslinking by olefin metathesis ${ }^{a}$

\begin{tabular}{cccccccc}
\hline $\begin{array}{c}\text { entry } \\
\text { no. }\end{array}$ & $\begin{array}{c}\text { st-PAMA } \\
\text { concentration } \\
\left(\mathrm{mg} \mathrm{mL}^{-1}\right)\end{array}$ & $\begin{array}{c}\mathrm{C}_{60} \\
\text { solution } \\
\left(\mathrm{mg} \mathrm{mL}^{-1}\right)\end{array}$ & solvent & $\begin{array}{c}T_{\mathrm{g}}{ }^{b} \\
\left({ }^{\circ} \mathrm{C}\right)\end{array}$ & $\begin{array}{c}T_{\mathrm{m}}{ }^{b} \\
\left({ }^{\circ} \mathrm{C}\right)\end{array}$ & $\begin{array}{c}\text { yield after } \\
\text { crosslinking } \\
(\%)\end{array}$ & $\begin{array}{c}\text { encapsulated } \\
\mathrm{C}_{60} \text { content } \\
(\mathrm{wt} \%)^{d}\end{array}$ \\
\hline 1 & 5.0 & 1.0 & Tol & 47.9 & 200 & n.d. & n.d. \\
2 & 5.0 & 2.0 & Tol & 53.1 & 206 & n.d. & n.d. \\
3 & 10.0 & 1.0 & Tol & 53.6 & 207 & $>99$ & 3.39 \\
4 & 10.0 & 2.0 & Tol & 52.8 & 205 & $>99$ & 4.77 \\
5 & 10.0 & 10.0 & Tol-DCB & 56.3 & 207 & $>99$ & 9.18 \\
6 & 20.0 & 1.0 & Tol & 52.6 & - & n.d. & n.d. \\
7 & 20.0 & 2.0 & Tol & 55.1 & 211 & n.d. & n.d. \\
8 & 20.0 & 10.0 & Tol-DCB & 57.3 & 207 & n.d. & n.d. \\
\hline
\end{tabular}

${ }^{a}$ Conditions: $2.0 \mathrm{~mL}$ solvent $(\mathrm{Tol}=$ toluene or Tol-DCB $=$ toluene/1,2-dichlorobenzene mixture in 50:50 vol\%), except for entries 1 and $2(5.0 \mathrm{~mL})$; Grubb's catalyst $2^{\text {nd }}$ Gen. $(2 \mathrm{~mol} \%)$; st-PAMA $\left(M_{\mathrm{n}}=39.9\right.$ $\mathrm{kDa}, Ð=1.45,[r r]=91.8)$; n.d. $=$ not determined. ${ }^{b} T_{\mathrm{g}}$ and $T_{\mathrm{m}}$ before crosslinking measured by DSC. Determined by gravimetric measurements. ${ }^{d}$ Calculated by TGA. 


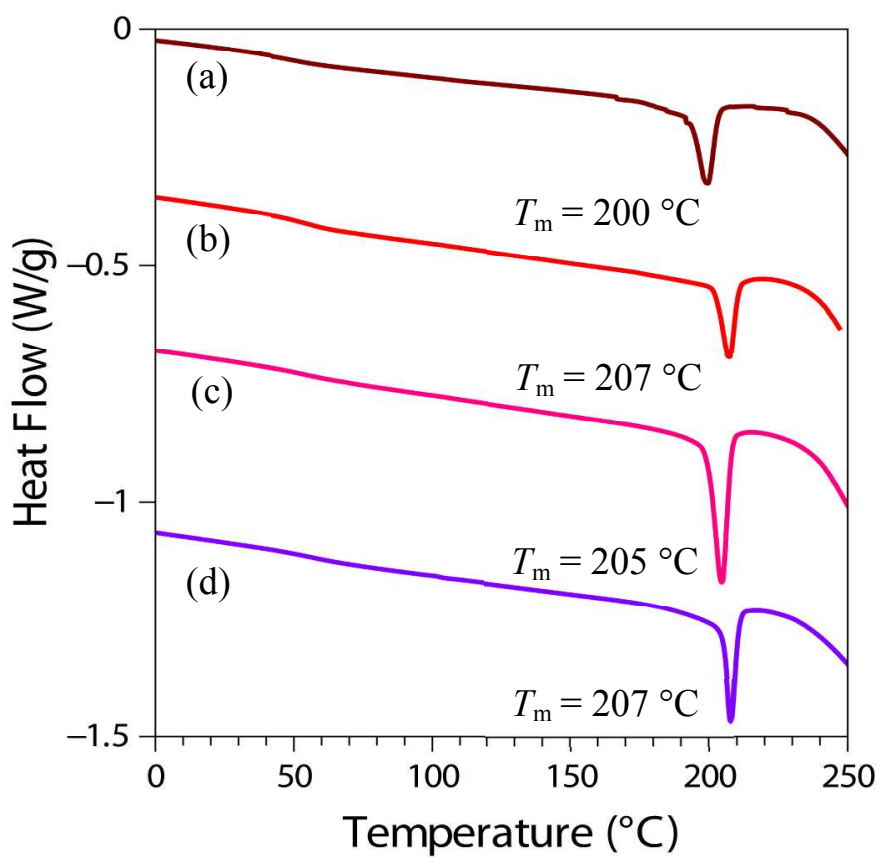

Figure 17. DSC thermograms $\left(10^{\circ} \mathrm{C} \mathrm{min}^{-1}\right)$ of $i c$-PAMA-C $\mathrm{C}_{60}$ produced from toluene solutions of $s t$ PAMA and $\mathrm{C}_{60}$ : Table 4 , entry 1 (a), entry 3 (b), entry 4 (c), and entry 8 (d).

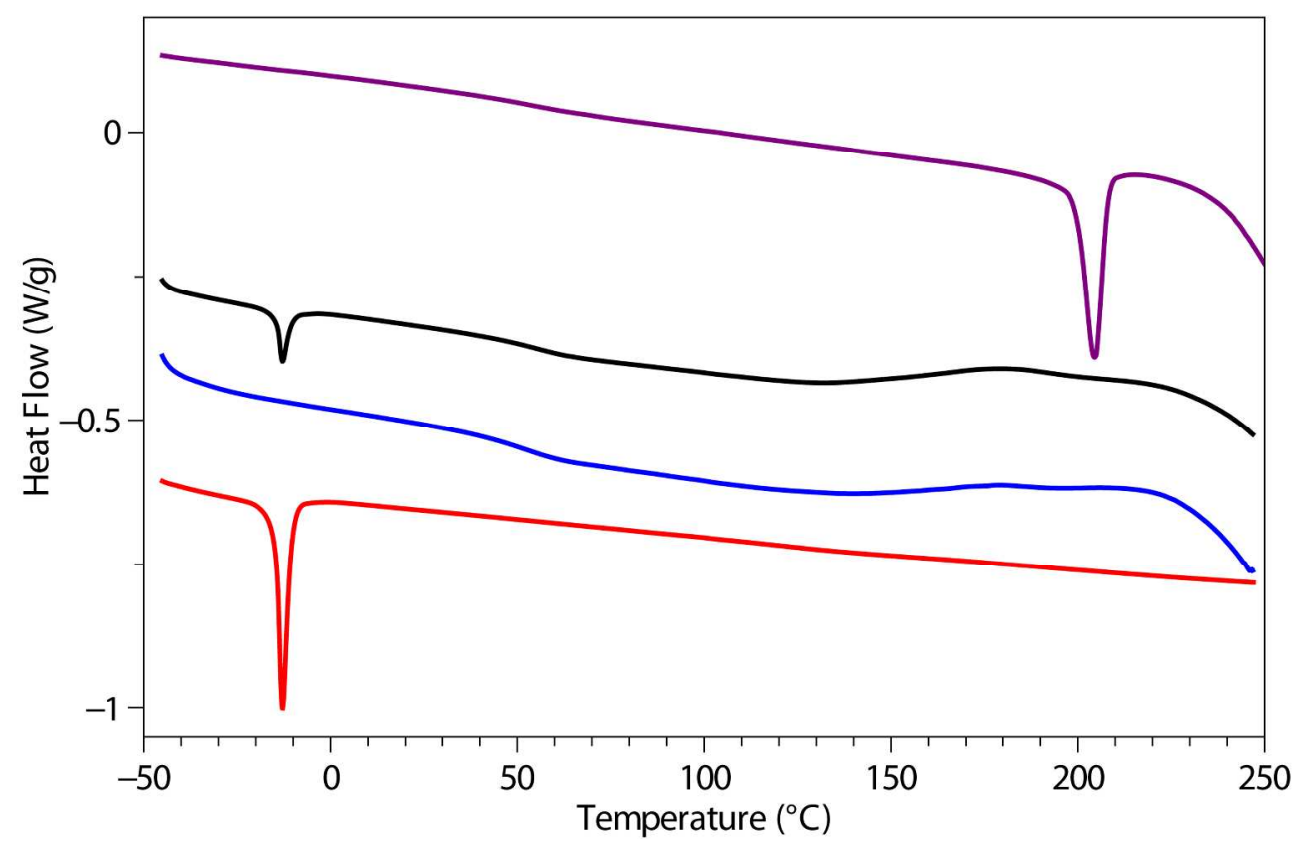

Figure 18. DSC $\left(10{ }^{\circ} \mathrm{C} \mathrm{min}^{-1}\right)$ thermograms of: commercial fullerene $\mathrm{C}_{60}$ powder (red); st-PAMA (blue); annealed blend of $s t$-PAMA $/ \mathrm{C}_{60}$ at $80{ }^{\circ} \mathrm{C}$ for $20 \mathrm{~h}$ (black); and ic-PAMA- $\mathrm{C}_{60}$ from Table 4 , entry 4 (purple). 
Once successfully crosslinked, the $\mathrm{C}_{60}$ encapsulated inside the network of crosslinked st-PAMA-C ${ }_{60}$ cannot be reversibly recovered by dissolution of the inclusion complex as it is no longer soluble in toluene. A control reaction was performed to assess the Ru catalyst residue in the crosslinked complex by performing a crosslinking reaction of st-PAMA under the same conditions but without $\mathrm{C}_{60}$. The content of $\mathrm{C}_{60}$ in the crosslinked complex was calculated through TGA analysis (Figure 19) by subtracting the residue in the trace at $500{ }^{\circ} \mathrm{C}$ of $s t-\mathrm{PAMA}-\mathrm{C}_{60}$, minus the control experiment (3.49 wt\%). These results indicated an uptake of $\mathrm{C}_{60}$ up to $9.18 \mathrm{wt} \%$ in the crosslinked $s t$-PAMA- $\mathrm{C}_{60}$ when a $10.0 \mathrm{mg} / \mathrm{mL}$ solution of $\mathrm{C}_{60}$ in the feed was employed.

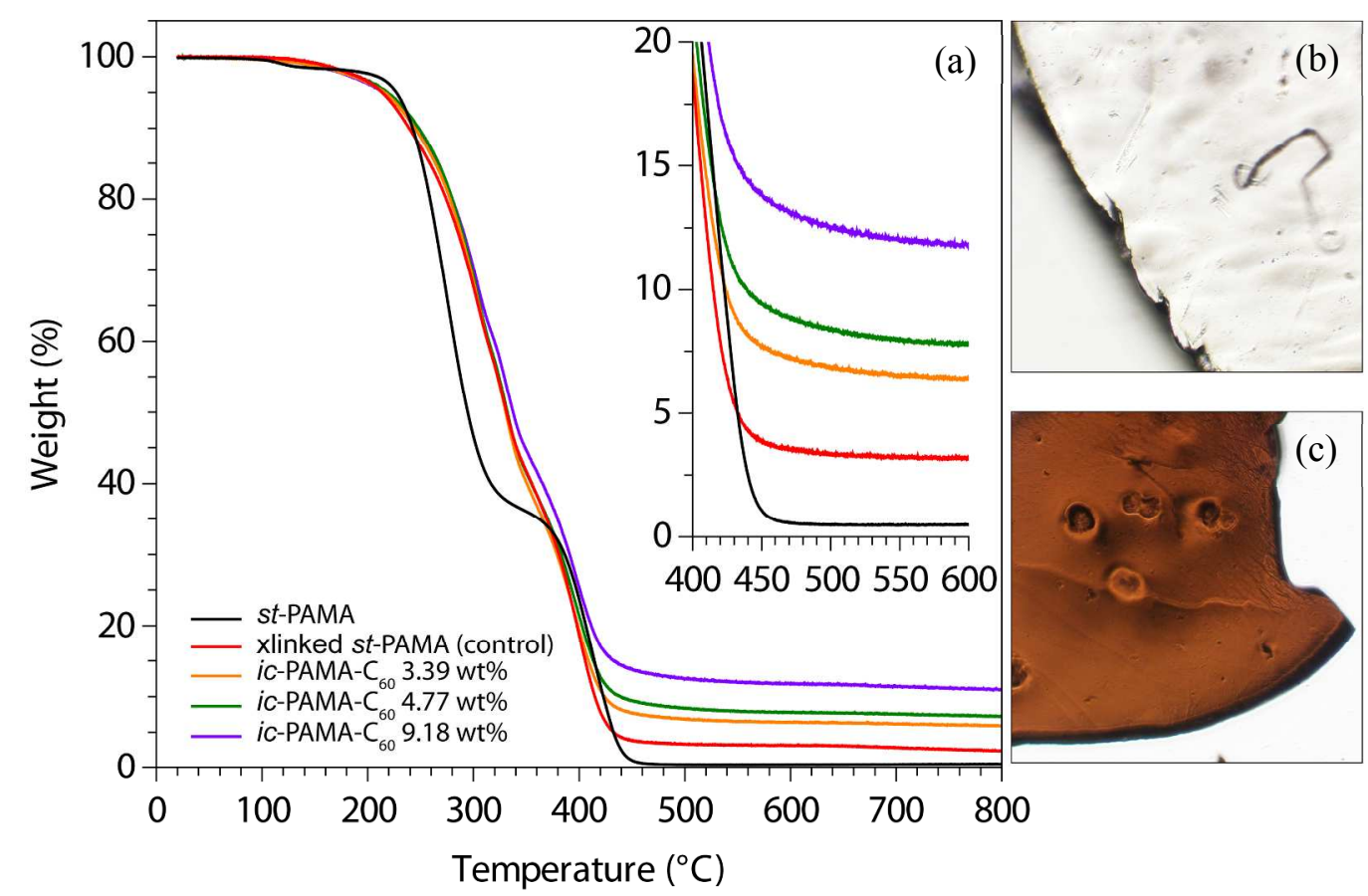

Figure 19. (a) TGA $\left(10{ }^{\circ} \mathrm{C} \mathrm{min}^{-1}\right)$ traces of $s t$-PAMA (black), crosslinked st-PAMA control (red), crosslinked ic-PAMA-C $603.43 \mathrm{wt} \%$ (orange), crosslinked $i c$-PAMA-C $604.77 \mathrm{wt} \%$ (green), and crosslinked $i c$-PAMA-C $609.18 \mathrm{wt} \%$ (purple); (b) microphotograph of st-PAMA film sample, and (c) microphotograph of crosslinked ic-PAMA- $\mathrm{C}_{60} 4.77 \mathrm{wt} \%$ film.

\section{Conclusions}


The perfectly chemoselective and highly syndiospecific coordination polymerization of divinyl polar monomers developed through this work has enabled the synthesis of highly syndiotactic polar vinyl polymers bearing the pendant reactive $\mathrm{C}=\mathrm{C}$ bond on each repeat unit. Polymerization of three representative polar divinyl monomers (AMA, VMA, and DAA) by the $C_{\mathrm{s}}$-ligated zirconocenium ester enolate catalysts under ambient conditions all achieved complete chemoselectivity and high stereoselectivity, producing the corresponding vinyl-functionalized polymers with syndiotacticity following this trend: st-PDAA $(>99 \% r r)>s t$-PVMA $(96 \% r r)>s t$-PAMA $(92 \% r r)$. Careful examination of the VMA polymerization by catalyst $\mathbf{5}$, including synthetic, kinetic and mechanistic studies, showed that the polymerization follows a unimetallic, enantiomorphic-site controlled mechanism through the cationic cyclic metallacycle resting intermediate and exhibits the ability to control the resulting polymer $M_{\mathrm{n}}$ and $\varnothing$ values. DFT calculations on free energy $\Delta G_{\text {Stereo }}$ of the transition state geometries for the competitive (correct and incorrect enantiofacial) additions in the polymerization of AMA and VMA provided a theoretical basis for the observed large difference in isotacticity of the polymers produced by $C_{2}$-ligated catalyst $\mathbf{1}$, but the rather similar syndiotacticity of the polymers produced by $C_{5}$-ligated catalyst 5 .

The pendant vinyl groups of the obtained syndiotactic polymers can be completely converted into the corresponding thiolated polymers of the same tacticity, via the thiol-end click reaction with different thiols. Such polymers can also be readily photocured into flexible, crosslinked thin films for examining their thermo-mechanical properties, which revealed an expected increase in $T_{\mathrm{g}}, E^{\prime}$, and $E^{\prime \prime}$ values as the degree of crosslinking increases.

Vinyl-functionalized syndiotactic polymers, st-PVMA and st-PAMA, can readily form crystalline stereocomplexes with it-PMMA in a 2:1 or 1:1 molar ratio, but st-PVMA appears to form a stronger stereocomplex, as evidenced by the observed higher $T_{\mathrm{m}}$, presumably due to the higher syndiotacticity of the constituent st-PVMA. Interestingly, it-PAMA also formed a weak stereocomplex with st-PMMA, and isotactic block copolymers it-PMMA- $b$-it-PAMA and it-PMMA-b-it-PVMA, but not their random 
copolymers, readily form crystalline stereocomplexes with either st-PAMA or st-PVMA; both findings extended the it-polymer capable of stereocomplexation beyond it-PMMA. The it-/st- stereocomplex, $s c$ PMMA-PVMA, can be readily photocured into a crosslinked, insoluble stereocomplex that exhibits high it-PMMA trapping efficiencies. Thermo-mechanical and X-ray diffraction analysis results showed that stereocomplex formation significantly increases storage and loss moduli over the constituent $i t$ - and $s t$ polymers at temperatures $>100{ }^{\circ} \mathrm{C}$ and that the photocured stereocomplex retains the stereocomplex structure but with considerably enhanced thermal and mechanical properties of the material.

$s t$-PAMA readily forms inclusion complexes, ic-PAMA- $\mathrm{C}_{60}$, with $\mathrm{C}_{60}$ in different ratio combinations. Crosslinking of ic-PAMA- $\mathrm{C}_{60}$ was achieved successfully via olefin metathesis using the Grubbs catalyst $\left(2^{\text {nd }}\right.$ Gen.), while the photocuring in the presence of the photoinitiator was unsuccessful, attributable to $\mathrm{C}_{60}$ being an excellent radical trap. The encapsulated $\mathrm{C}_{60}$ in the resulting crosslinked stPAMA- $\mathrm{C}_{60}$ can no longer be released by dissolution of the inclusion complex, in contrast to the uncrosslinked inclusion complex.

Supplementary Information. Full experimental details and additional figures (54 pages). This material is available free of charge on the ACS Publications website.

Acknowledgments. This work was supported by the US National Science Foundation (NSF1300267) for the study carried out at Colorado State University. L. Cavallo thanks the HPC team of Enea (www.enea.it) for using the ENEA-GRID and the HPC facilities CRESCO (www.cresco.enea.it) in Portici, Italy. We thank Boulder Scientific Co. for the research gifts of $\mathrm{B}\left(\mathrm{C}_{6} \mathrm{~F}_{5}\right)_{3}$ and $\left[\mathrm{Ph}_{3} \mathrm{C}\right]\left[\mathrm{B}\left(\mathrm{C}_{6} \mathrm{~F}_{5}\right)_{4}\right]$.

\section{References}

(1) Selected reviews: (a) Stereoselective Polymerization with Single-Site Catalysts, Baugh, L. S.; Canich, J. A. M., Eds.; CRC Press/Taylor \& Francis Group: Boca Raton, FL, 2008. (b) Resconi, L.; Chadwick, J. C.; Cavallo, L. in Comprehensive Organometallic Chemistry III; Bochmann, M. Vol. 
Ed.; Mingos, M. P.; Crabtree, R. H. Chief Eds.; Elsevier: Oxford, 2007; Vol. 4, pp 1005-1166. (c) Coates, G. W. Chem. Rev. 2000, 100, 1223-1252. (d) Brintzinger, H. H.; Fischer, D.; Mülhaupt, R.; Rieger, B.; Waymouth, R. M. Angew. Chem., Int. Ed. 1995, 34, 1143-1170.

(2) Selected recent examples and reviews: (a) Jian, Z.; Baier, M. C.; Mecking, S. J. Am. Chem. Soc. 2015, 137, 2836-2839. (b) Ota, Y.; Ito, S.; Kuroda, J.; Okumura, Y.; Nozaki, K. J. Am. Chem. Soc. 2014, 136, 11898-11901. (c) Nakamura, A.; Anselment, T. M. J.; Claverie, J. P.; Goodall, B.; Jordan, R. F.; Mecking, S.; Rieger, B.; Sen, A.; van Leeuwen, P. W. N. M.; Nozaki, K. Acc. Chem. Res. 2013, 46, 1438-1449. (d) Delferro, M.; Marks, T. J. Chem. Rev. 2011, 111, 2450-2485. (e) Nakamura, A.; Ito, S.; Nozaki, K. Chem. Rev. 2009, 109, 5215-5244. (f) Berkefeld, A.; Mecking, S. Angew. Chem., Int. Ed. 2008, 47, 2538-2542. (g) Luo, S.; Vela, J.; Lief, G. R.; Jordan, R. F. J. Am. Chem. Soc. 2007, 129, 8946-8947. (h) Domski, G. J.; Rose, J. M.; Coates, G. W.; Bolig, A. D.; Brookhart, M. Prog. Polym. Sci. 2007, 32, 30-92. (i) Jensen, T. R.; Yoon, S. C.; Dash, A. K.; Luo, L.; Marks, T. J. J. Am. Chem. Soc. 2003, 125, 14482-14494. (j) Gibson, V. C.; Spitzmesser, S. K. Chem. Rev. 2003, 103, 283-315. (k) Coates, G. W.; Hustad, P. D.; Reinartz, S. Angew. Chem. Int. Ed. Engl. 2002, 41, 2236-2257. (1) Ittel, S. D.; Johnson, L. K.; Brookhart, M. Chem. Rev. 2000, $100,1169-1204$.

(3) Selected reviews: (a) Soller, B. S.; Salzinger, S.; Rieger, B. Chem. Rev. 2016, 116, 1993-2022. (b) Chen, E. Y.-X. Chem. Rev. 2009, 109, 5157-5214. (c) Yasuda, H. Prog. Polym. Sci. 2000, $25,573-626$.

(4) Selected examples: (a) Zhang, N.; Salzinger, S.; Soller, B. S.; Rieger, B. J. Am. Chem. Soc. 2013, 135, 8810-8813. (b) Chen, X.; Caporaso, L.; Cavallo, L.; Chen, E. Y.-X. J. Am. Chem. Soc. 2012, 134, 7278-7281. (c) Miyake, G. M.; Mariott, W. R.; Chen, E. Y.-X. J. Am. Chem. Soc. 2007, 129, 6724-6725. (d) Lian, B.; Spanio, T. P.; Okuda, J. Organometallics 2007, 26, 6653-6660. (e) Lian, B.; Thomas, C. M.; Navarro, C.; Carpentier, J.-F. Organometallics 2007, 26, 187-195. (f) 
Stojcevic, G.; Kim, H.; Taylor, N. J.; Marder, T. B.; Collins, S. Angew. Chem. Int. Ed. 2004, 43, 5523-5526. (g) Strauch, J. W.; Fauré, J.-L.; Bredeau, S.; Wang, C.; Kehr, G.; Fröhlich, R.; Luftmann, H.; Erker, G. J. Am. Chem. Soc. 2004, 126, 2089-2104. (h) Frauenrath, H.; Keul, H.; Höcker, H. Macromolecules 2001, 34, 14-19. (i) Bandermann, F.; Ferenz, M.; Sustmann, R.; Sicking, W. Macromol. Symp. 2001, 174, 247-253. (j) Cameron, P. A.; Gibson, V.; Graham, A. J. Macromolecules 2000, 33, 4329-4335. (k) Li, Y.; Ward, D. G.; Reddy, S. S.; Collins, S. Macromolecules 1997, 30, 1875-1883. (1) Deng, H.; Shiono, T.; Soga, K. Macromolecules 1995, 28, 3067-3073. (m) Collins, S.; Ward, S. G. J. Am. Chem. Soc. 1992, 114, 5460-5462. (n) Yasuda, H.; Yamamoto, H.; Yokota, K.; Miyake, S.; Nakamura, A. J. Am. Chem. Soc. 1992, 114 , 4908-4909.

(5) (a) Gao, H.; Matyjaszewski, K. Prog. Polym. Sci. 2009, 34, 317-350. (b) Li, Z.; Day, M.; Ding, J.; Faid, K. Macromolecules 2005, 38, 2620-2625. (c) Percec, V.; Auman, B. C. Macromol. Chem. Phys. 1984, 185, 2319-2336.

(6) Selected examples: (a) Sugiyama, F.; Satoh, K.; Kamigaito, M. Macromolecules 2008, 41, 3042-3048. (b) Ma, J.; Cheng, C.; Sun, G. R.; Wooley, K. L. Macromolecules 2008, 41, 9080-9089. (c) Vardareli, T. K.; Keskin, S.; Usanmaz, A. J. Macromol. Sci., Part A: Pure Appl. Chem. 2008, 45, 302-311. (d) París, R. J.; Fuente, L. D. J. Polym. Sci., Part A: Polym. Chem. 2005, 43, 6247-6261. (e) París, R. J.; Fuente, L. D. J. Polym. Sci., Part A: Polym. Chem. 2005, 43, 2395-2406. (f) Nagelsdiek, R.; Mennicken, M.; Maier, B.; Keul, H.; Hartwig, H. Macromolecules 2004, 37, 8923-8932.

(7) Pugh, C.; Percec, V. Polym. Bull. 1985, 14, 109-116.

(8) Selected examples: (a) Mohan, Y. M.; Raghunadh, V.; Sivaram, S.; Baskaran, D. Macromolecules 2012, 45, 3387-3393. (b) Lu, Z.; Lee, S. Y.; Goh, S. H. Polymer 1997, 38, 5893-5895. (c) Fukuda, 
W.; Nakao, M.; Okumura, K.; Kakiuchi, H. J. Polym. Sci. Part A: Polym. Chem. 1972, 10, $237-250$.

(9) Chen, E. Y.-X. Top. Curr. Chem. 2013, 334, 239-260.

(10) (a) Chen, J.; Chen, E. Y.-X. Isr. J. Chem. 2015, 55, 216-225. (b) Jia, Y.-B.; Ren, W.-M.; Liu, S.-J.; Xu, T.; Wang, Y.-B.; Lu, X.-B. ACS Macro Lett. 2014, 3, 896-899.

(11) Xu, T.; Liu, J.; Lu, X.-B. Macromolecules 2015, 48, 7428-7434.

(12) Bolig, A. D.; Chen, E. Y.-X. J. Am. Chem. Soc. 2004, 126, 4897-4906.

(13) Rodriguez-Delgado, A.; Chen, E. Y.-X. Macromolecules 2005, 38, 2587-2594.

(14) (a) Mariott, W. R.; Chen, E. Y.-X. Macromolecules 2005, 38, 6822-6832. (b) Mariott, W. R.; Chen, E. Y.-X. Macromolecules 2004, 37, 4741-4743.

(15) Vidal, F.; Gowda, R. R.; Chen, E. Y.-X. J. Am. Chem. Soc. 2015, 137, 9469-9480.

(16) Selected examples of sc-PMMA: (a) Ren, J. M.; Satoh, K.; Goh, T. K.; Blencowe, A.; Nagai, K; Ishitake, K.; Christofferson, A. J.; Yiapanis, G.; Yarovsky, I.; Kamigaito, M.; Qiao, G. G. Angew. Chem. Int. Ed. 2014, 53, 459-464. (b) Goh, T. K.; Tan, J. F.; Guntari, S. N.; Satoh, K.; Blencowe, A.; Kamigaito, M.; Qiao, G. G. Angew. Chem. Int. Ed. 2009, 48, 8707-8711. (c) Kawauchi, T.; Kumaki, J.; Yashima, E. J. Am. Chem. Soc. 2006, 128, 10560-10567. (d) Kawauchi, T.; Kumaki, J.; Okoshi, K.; Yashima, E. Macromolecules 2005, 38, 9155-9160. (e) Serizawa, T.; Hamada, K.-I.; Akashi, M. Nature 2004, 429, 52-55. (f) Slager, J.; Domb, A. J. Adv. Drug Delivery Rev. 2003, 55, 549-583. (g) Serizawa, T.; Hamada, K.; Kitayama, T.; Fujimoto, N.; Hatada, K.; Akashi, M. J. Am. Chem. Soc. 2000, 122, 1891-1899. (h) Hatada, K.; Kitayama, T.; Ute, K.; Nishiura, T. Macromol. Symp. 1998, 132, 221-230. (i) te Nijenhuis, K. Adv. Polym. Sci. 1997, 130, 67-81; 244-246. (j) Spevacek, J.; Schneider, B. Adv. Colloid Interface Sci. 1987, 27, 81-150. (k) Watanabe, W. H.; Ryan, C. F.; Fleischer, Jr. D. C.; Garret, B. S. J. Phys. Chem. 1961, 65, 896-896. (1) Fox, T. G.; 
Garret, B. S.; Goode, W. E.; Gratch, S.; Rincaid, J. F.; Spell, A.; Stroupe, J. D. J. Am. Chem. Soc. 1958, $80,1768-1769$.

(17) (a) Christofferson, A. J.; Yiapanis, G.; Ren, J. M.; Qiao, G. G.; Satoh, K.; Kamigaito, M.; Yarovsky, I. Chem. Sci. 2015, 6, 1370-1378. (b) Kumaki, J.; Kawauchi, T.; Ute, K.; Kitayama, T.; Yashima, E. J. Am. Chem. Soc. 2008, 130, 6373-6380. (c) Kumaki, J.; Kawauchi, T.; Okoshi, K.; Kusanagi, H.; Yashima, E. Angew. Chem. Int. Ed. 2007, 46, 5348-5351. (d) Schomaker, E.; G. Challa, G. Macromolecules 1989, 22, 3337-3341. (e) Bosscher, G.; ten Brinke, G.; Eshuis, A.; Challa, G. Macromolecules 1982, 15, 1364-1368. (f) Kusanagi, H.; Tadokoro, H.; Chatani, Y. Macromolecules 1976, 9, 531-532. (g) Liquori, A. M.; Anzuino, G.; Coiro, V. M.; D'Alagni, M.; de Santis, P.; Savino, M. Nature 1965, 206, 358-362.

(18) (a) Asai, S.; Kawano, T.; Hirota, S.-I.; Tominaga, Y.; Sumita, M.; Mizumoto, T. Polymer 2007, 48, 5116-5124. (b) Schomaker, E.; Challa, G. Macromolecules 1988, 21, 2195-2203. (c) Bosscher, F.; ten Brinke, G.; Challa, G. Macromolecules 1982, 15, 1442-1444.

(19) (a) Hatada, K.; Kitayama, T.; Ute, K.; Fujimoto, N.; Miyatake, N. Macromol. Symp. 1994, 84, 113126. (b) Kitayama, T.; Fujimoto, N.; Hatada, K. Polym. Bull. 1991, 26, 629-636.

(20) Escudé, N. C.; Ning, Y.; Chen, E. Y.-X. Polym. Chem. 2012, 3, 3247-3255.

(21) Mariott, W. R.; Escudé, N. C.; Chen, E. Y.-X. J. Polym. Sci. Part A: Polym. Chem. 2007, 45, $2581-2592$.

(22) Mariott, W. R.; Chen, E. Y.-X. J. Am. Chem. Soc. 2003, 125, 15726-15727.

(23) Escudé, N. C.; Chen, E. Y.-X. Chem. Mater. 2009, 21, 5743-5753.

(24) (a) Kusuyama, H.; Miyamoto, N.; Chatani, Y.; Tadokoro, H. Polymer 1983, 24, 119-122. (b) Kusuyama, H.; Takase, M.; Higashihara, Y.; Tseng, H.-T.; Chatani, Y.; Tadokoro, H. Polymer 1982, 23, 1256-1258. 
(25) (a) Kawauchi, T.; Kitaura, A.; Kawauchi, M.; Takeichi, T.; Kumaki, J.; Lida, H.; Yashima, E. $J$. Am. Chem. Soc. 2010, 132, 12191-12193. (b) Kawauchi, M.; Kawauchi, T.; Takeichi, T. Macromolecules 2009, 42, 6136-6140. (c) Kawauchi, T.; Kitaura, A.; Kumaki, J.; Kusanagi, H.; Yashima, E. J. Am. Chem. Soc. 2008, 130, 11889-11891. (d) Kawauchi, T.; Kumaki, J.; Kitaura, A.; Okoshi, K.; Kusanagi, H.; Kobayashi, K.; Sugai, T.; Shinohara, H.; Yashima, E. Angew. Chem. Int. Ed. 2008, 47, 515-519.

(26) (a) Zhang, Y.; Ning, Y.; Caporaso, L.; Cavallo, L.; Chen, E. Y.-X. J. Am. Chem. Soc. 2010, 132, 2695-2709. (b) Ning, Y.; Chen, E. Y.-X. J. Am. Chem. Soc. 2008, 130, 2463-2465.

(27) Zhang, Y.; Caporaso, L.; Cavallo, L.; Chen, E. Y.-X. J. Am. Chem. Soc. 2011, 133, 1572-1588.

(28) (a) Caporaso, L.; Cavallo, L. Macromolecules 2008, 41, 3439-3445. (b) Caporaso, L.; GraciaBudrìa, J.; Cavallo, L. J. Am. Chem. Soc. 2006, 128, 16649-16654.

(29) For selected reviews, see: (a) Barner-Kowollik, C.; Du Prez, F. E.; Espeel, P.; Hawker, C. J.; Junkers, T.; Schlaad, H.; Van Camp, W. Angew. Chem. Int. Ed. 2011, 50, 60-62. (b) Hoyle, C. E.; Bowman, C. N. Angew. Chem. Int. Ed. 2010, 49, 1540-1573. (c) Iha, R. K.; Wooley, K. L.; Nyström, A. M.; Burke, D. J.; Kade, M. J.; Hawker, C. J. Chem. Rev. 2009, 109, 5620-5686. (d) Binder, W. H.; Sachsenhofer, R. Macromol. Rapid Commun. 2008, 29, 952-981. (e) Binder, W. H.; Sachsenhofer, R. Macromol. Rapid Commun. 2007, 28, 15-54.

(30) (a ) Skokan, E. V.; Alioshina, V. E.; Spiridonov, F. M.; Arkhangelsky, I. V.; Davydov, V. Y.; Tamm, N. B.; Sidorov, L. N. J. Phys. Chem. 1995, 99, 16116-16118. (b) Saito, R.; Dresselhaus, G.; Dresselhaus, M. S. Phys. Rev. B 1994, 49, 2143-2147. (c) Fischer, J. E.; Luzzi, D. E.; Kniaź, K.; McGhie, A. R.; Ricketts-Foot, D. A.; Romanow, W. R.; Vaughan, G. B. M.; Heiney, P. A.; Li, D.; Smith, A. L.; Strongin, R. M.; Cichy, M. A.; Brard, L.; Smith, A. B. Phys. Rev. B 1993, 47, 1461414617. (d) Heiney, P. A.; Fischer, J. E.; McGhie, A. R.; Romanow, W. J.; Denenstein, A. M.; McCauley Jr, J. P.; Smith, A. B.; Cox, D. E. Phys. Rev. Lett. 1991, 66, 2911-2914. 
1

2

3

4

5

6

7

8

9

10

11

12

13

14

15

16

17

18

19

20

21

22

23

24

25

26

27

28

29

30

31

32

33

34

35

36

37

38

39

40

41

42

43

44

45

46

47

48

49

50

51

52

53

54

55

56

57

58

59

60

(31) Tzirakis, M. D.; Orfanopoulos, M. Chem. Rev. 2013, 113, 5262-5321.

(32) Scholl, M.; Ding, S.; Lee, C. W.; Grubbs, R. H. Org. Let. 1999, 1, 953-956.

For Table of Contents Use Only

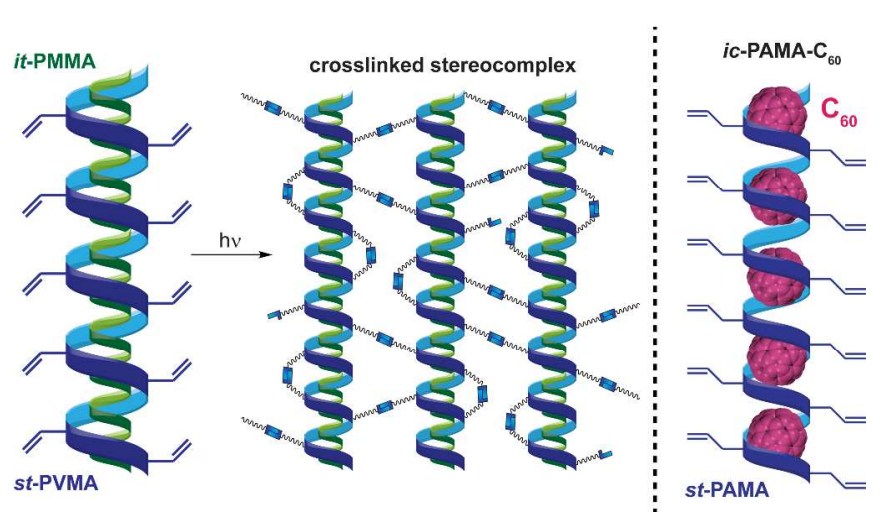

